\title{
Simultaneous ground-based and in situ Swarm observations of equatorial F-region irregularities over Jicamarca
}

\author{
Sharon Aol ${ }^{1}$, Stephan Buchert ${ }^{2}$, Edward Jurua ${ }^{1}$, and Marco Milla ${ }^{3}$ \\ ${ }^{1}$ Mbarara University of Science and Technology, Department of Physics, Mbarara, Uganda \\ ${ }^{2}$ Swedish Institute of Space Physics, Uppsala, Sweden \\ ${ }^{3}$ Radio Observatorio de Jicamarca, Instituto Geofísico del Perú, Lima, Peru
}

Correspondence: Sharon Aol (saol@must.ac.ug)

Received: 8 November 2019 - Discussion started: 3 December 2019

Revised: 22 July 2020 - Accepted: 17 August 2020 - Published: 16 October 2020

\begin{abstract}
Ionospheric irregularities are a common phenomenon in the low-latitude ionosphere. They can be seen in situ as depletions of plasma density, radar plasma plumes, or ionogram spread $\mathrm{F}$ by ionosondes. In this paper, we compared simultaneous observations of plasma plumes by the Jicamarca Unattended Long-term Investigations of the Ionosphere and Atmosphere (JULIA) radar, ionogram spread F generated from ionosonde observations installed at the Jicamarca Radio Observatory (JRO), and irregularities observed in situ by Swarm in order to determine whether Swarm in situ observations can be used as indicators of the presence of plasma plumes and spread $\mathrm{F}$ on the ground. The study covered the years from 2014 to 2018, as this was the period for which JULIA, Swarm, and ionosonde data sets were available. Overall, the results showed that Swarm's in situ density fluctuations on magnetic flux tubes passing over (or near) the JRO may be used as indicators of plasma plumes and spread F over (or near) the observatory. For Swarm and the groundbased observations, a classification procedure was conducted based on the presence or absence of ionospheric irregularities. There was a strong consensus between ground-based observations of ionospheric irregularities and Swarm's depth of disturbance of electron density for most passes. Cases, where ionospheric irregularities were observed on the ground with no apparent variation in the in situ electron density or vice versa, suggest that irregularities may either be localized horizontally or restricted to particular height intervals. The results also showed that the Swarm and ground-based observations of ionospheric irregularities had similar local time statistical trends with the highest occurrence obtained between 20:00 and 22:00 LT. Moreover, similar seasonal pat-
\end{abstract}

terns of the occurrence of in situ and ground-based ionospheric irregularities were observed with the highest percentage occurrence at the December solstice and the equinoxes and low occurrence at the June solstice. The observed seasonal pattern was explained in terms of the pre-reversal enhancement (PRE) of the vertical plasma drift. Initial findings from this research indicate that fluctuations in the in situ density observed meridionally along magnetic field lines passing through the JRO can be used as an indication of the existence of well-developed plasma plumes.

\section{Introduction}

Generally, the ionosphere can be viewed as a layer with a relatively uniform plasma density distribution (Ngwira et al., 2013). However, the night-time low-latitude ionosphere is characterized by localized plasma density structures, known as ionospheric irregularities (Stolle et al., 2006). The equatorial ionospheric irregularities may be identified as irregular plasma density "bite-outs" observed in situ along low Earth orbit (LEO) satellite tracks in the topside ionosphere (Woodman and La Hoz, 1976; Tsunoda, 1980; Tsunoda et al., 1982; Kelley, 2009). The equatorial ionospheric irregularities may also manifest as equatorial spread-F (ESF) signatures, which are irregular signatures on ionograms due to backscattering from the bottom side of the nighttime Flayer and also above (Woodman and La Hoz, 1976; Hysell and Burcham, 1998). Ionospheric irregularities have also been called plasma plumes because of their appearance in range versus time radar displays (Woodman and La Hoz, 
1976). The plumes are characterized by elongated, wedgelike cross sections that extend from the bottom of the $\mathrm{F}$ layer to higher altitudes (Tsunoda, 1980; Tsunoda et al., 1982; Ma and Maruyama, 2006). Equatorial ionospheric irregularities usually extend along magnetic field lines to magnetic latitudes of about $\pm 15^{\circ}$ to $\pm 20^{\circ}$ (Ossakow, 1979; Kil and Heelis, 1998; Nishioka et al., 2008; Kelley, 2009).

Ionospheric irregularities in the low latitudes arise after sunset due to the Rayleigh-Taylor instability (RTI) which originates from the lower $\mathrm{F}$ region (Woodman and La Hoz, 1976; Kelley, 2009; Schunk and Nagy, 2009). These irregularities vary with respect to scale, from several centimetres to hundreds of kilometres (Lühr et al., 2014; Xiong et al., 2016; Rino et al., 2016). A width of about $100 \mathrm{~km}$ was observed for the depleted ESF bands using an all-sky airglow imager (Otsuka et al., 2004). The occurrence of ionospheric irregularities varies according to local time, season, longitude, latitude, and solar and magnetic activity (Kil et al., 2009). Their occurrence is a subject of interest because of the effect they have on propagating radio signals. Their presence in the ionosphere may cause amplitude and phase scintillations of radio signals, thereby affecting many applications that rely on these signals (Yeh and Liu, 1982).

Equatorial ionospheric irregularities have been observed many times using ground-based instruments, such as incoherent and coherent scatter radars, ionosonde, and airglow cameras, and space-based instruments, such as rockets and LEO satellites (e.g. Woodman and La Hoz, 1976; Hysell et al., 1997; Nishioka et al., 2008; Fejer et al., 1999; Burke et al., 2003; Sripathi et al., 2008; Wang et al., 2015; Hickey et al., 2018; Aa et al., 2020). It should be noted that although ionospheric irregularities have been studied extensively, uncertainties still exist in understanding their evolution because of their varying scale with respect to size (Abdu, 2001; Sripathi et al., 2008; Aa et al., 2020). In this regard, different instruments are limited to observing ionospheric irregularities of specific sizes (Sripathi et al., 2008; Aa et al., 2020). Therefore, coordinated observation of ionospheric irregularities using different instruments is an effective way to generate an integrated and comprehensive image for specifying ionospheric irregularities of different sizes (e.g. Sripathi et al., 2008; Cherniak et al., 2019; Aa et al., 2019, 2020). Specifically, the Jicamarca Radio Observatory (JRO) has provided a rare opportunity to observe ionospheric irregularities using multiple ground-based instruments due to its strategic location $\left(12.0^{\circ} \mathrm{S}, 76.8^{\circ} \mathrm{W}\right.$; magnetic latitude $\left.0.6^{\circ} \mathrm{S}\right)$ at the magnetic equator. Many studies have reported the connection between scintillation-producing ionospheric irregularities observed by JULIA and equatorial plasma bubbles (EPBs) observed in situ over Jicamarca (e.g. Morse et al., 1977; Basu et al., 1980; Hysell and Burcham, 2002; Burke et al., 2003; Kelley et al., 2009; Siefring et al., 2009; Roddy et al., 2010; Nishioka et al., 2011). However, the relationship between metre-scale irregularities detected by coherent scatter radars and the underlying state parameters of the ionospheric plasma is not yet well understood (Hysell et al., 2009). Previous studies (e.g. Kelley et al., 2009; Siefring et al., 2009; Hysell et al., 2009; Roddy et al., 2010; Nishioka et al., 2011) have mostly compared zonally oriented in situ plasma density measurements from the Communication Navigation Outage Forecasting System (C/NOFS) satellite with JULIA observations. The European Space Agency's Swarm satellites neatly revisit the JRO in orbits oriented in the meridional direction, providing a renewed opportunity to study in situ ionospheric irregularities recorded by Swarm in the meridional direction in comparison with observations from Jicamarca.

A quantitative statistical relationship between plasma bubbles observed in situ in the meridional direction, $250 \mathrm{MHz}$ amplitude scintillation, and JULIA observations was reported by Burke et al. (2003) using data recorded by the polar-orbiting Defense Meteorological Satellite Program (DMSP). From the observations made by Burke et al. (2004), the plasma plumes recorded by JULIA frequently occurred at altitudes lower than that of the DMSP orbit. Most of the plasma plumes failed to reach altitudes $>600 \mathrm{~km}$ and, therefore, were not observed by DMSP satellites that orbited at an altitude of about $840 \mathrm{~km}$. It is possible to compare in situ measurements made by Swarm and JULIA observations at altitudes of $460 \mathrm{~km}$ (Swarm A and C) and $510 \mathrm{~km}$ (Swarm B). In contrast to DMSP, Swarm allows a comparison of measurements from identical instruments at different altitudes and in different longitudinal sectors (Zakharenkova et al., 2016). Previous comparison of Swarm in situ measurements with ground-based radar observations (e.g. Zakharenkova et al., 2016) mostly used Langmuir Probe (LP) measurements at a $2 \mathrm{~Hz}$ frequency. The faceplate carried by Swarm as part of the electric field instrument (EFI) has enabled the discovery of small-scale (down to $500 \mathrm{~m}$ length along the spacecraft track) ionospheric irregularities. Moreover, the previous comparison of Swarm in situ measurements with groundbased radar observations was mostly a single-case presentation. Zakharenkova et al. (2016) demonstrated that the gradual spatial separation between Swarm A, C, and B would decrease the likelihood that all three satellites could capture ionospheric irregularity signatures in the same localized region or near particular equipment installed on the ground, such as ionosonde and radars. Nevertheless, only one single case of comparison between Swarm and JULIA observation was provided by Zakharenkova et al. (2016).

In this paper, we quantitatively compared the in situ observations of ionospheric irregularities recorded by the Swarm satellites with ground-based measurements of plasma plumes made by the JULIA radar for the years from 2014 to 2018 in order to determine whether Swarm in situ observations can be used as indicators of the presence of plasma plumes and spread F on the ground. The comparison is complemented by ionosonde measurements of spread $\mathrm{F}$ over the JRO. Booker and Wells (1938) observed echoes on ionograms from ionosonde observations and proposed that these 
echo signatures were originating from ionosphere disturbances. As far as we know, Wang et al. (2015) were among the first to make concurrent observations of strong range spread $\mathrm{F}$ and ionospheric irregularities measured in situ using the ROCSAT-1 satellite; they found that strong spread $\mathrm{F}$ were caused by the ionospheric irregularities. However, ROCSAT-1 orbited at an altitude of about $600 \mathrm{~km}$ with a $35^{\circ}$ orbital inclination. Therefore, we also compared the JULIA and Swarm observations of ionospheric irregularities with spread-F signatures recorded by an ionosonde colocated with the JULIA radar. To understand the range of altitude above sea level where ionospheric irregularities occur and the effect that they have on ground observations, a comparison of in situ electron density variation with groundbased measurements over a long time period is essential.

This paper is organized as follows: in Sect. 2, the data and methods used in this study are described; in Sect. 3, the results are presented and discussed; and the findings of this study are summarized in Sect. 4.

\section{Data and methods}

\subsection{Data}

This section provides brief descriptions of the instruments and data sets used to examine the signatures of ionospheric irregularities in this research: we analysed data obtained from Swarm, the JULIA radar, and ionosonde.

\subsubsection{Swarm measurements of electron density}

The Swarm mission consists of three polar-orbiting satellites - Swarm A, B, and C (Friis-Christensen et al., 2006). They were launched into near-polar orbits at an initial altitude of about $500 \mathrm{~km}$ on 22 November 2013 (Xiong et al., 2016; Wan et al., 2018). Each satellite is equipped with an electric field instrument (EFI) that is mounted on the ram side of the spacecraft (Friis-Christensen et al., 2006; Knudsen et al., 2017). The ion density $N_{\mathrm{i}}$ is derived from the EFI faceplate current assuming that the current is carried by ions hitting the faceplate due to the orbital motion of the spacecraft (Buchert, 2016). However, due to quasi-neutrality, $N_{\mathrm{i}}$ must be equal to the electron density $N_{\mathrm{e}}$. With the $16 \mathrm{~Hz}$ $N_{\mathrm{e}}$ measurements, Swarm observes ionospheric irregularities with sizes of up to $500 \mathrm{~m}$. Friis-Christensen et al. (2006) and Knudsen et al. (2017) provide detailed information on Swarm and the onboard instruments. In this study, we used the $16 \mathrm{~Hz} N_{\mathrm{e}}$ measurements to examine topside ionospheric irregularities. The faceplate $N_{\mathrm{e}}$ data are readily available at http://earth.esa.int/swarm (last access: 23 February 2020).

\subsubsection{The JULIA radar}

The JULIA radar is a PC-based system for data acquisition. JULIA uses low-power transmitters with a frequency of ap- proximately $50 \mathrm{MHz}$ and Jicamarca's main antenna (Hysell and Burcham, 1998, 2002; Burke et al., 2003). Its aim is to record ionospheric irregularities and neutral atmospheric waves at the equatorial region for long periods of time. The pulse width used in the JULIA experiments during the period of study was $25 \mu$ s, and the pulse repetition was 160 pulses per second. In addition, 248 range gates that were separated by $3.75 \mathrm{~km}$ were sampled - from $0 \mathrm{~km}$ to about $930 \mathrm{~km} \mathrm{-}$ during the period of study. For the identification of $3 \mathrm{~m}$ scale ionospheric irregularities, the backscattered $50 \mathrm{MHz}$ JULIA radar echo was used. The radar observations provide the signal-to-noise ratio (SNR), Doppler velocity, and spectral width as a function of height and time. Data collected by the JULIA radar are readily available at http://jro.igp.gob.pe/ madrigal/ (last access: 23 February 2020). The website provides JULIA data from 1996 to date. Our analysis was restricted to the years from 2014 to 2018, as this was the period for which JULIA, Swarm, and ionosonde data sets were available.

\subsubsection{The digital ionosonde}

The equatorial spread-F (ESF) signatures are often recorded by ionosondes installed at the JRO. The ionosonde at the JRO is a Digisonde DPS-4 (Reinisch et al., 1998) which records ionograms (altitude versus frequency plots) at $15 \mathrm{~min}$ intervals. The Automatic Real-Time Ionogram Scaler with True height (ARTIST) ionogram autoscaling tool, developed at University of Massachusetts Lowell Center for Atmospheric Research (UMLCAR), is used to scale the ionograms, and the outputs are plasma frequency profiles versus altitude (Reinisch et al., 2005; Zhang et al., 2015). The equatorial spread-F signatures were analysed from the ionograms. The ionosonde data are also available on the Madrigal website, and we used all of the Jicamarca ionograms for the years from 2014 to 2018.

\subsection{Methods}

This section presents the analysis techniques used in this study to identify the observed ionospheric irregularity signatures with Swarm, JULIA, and the ionosonde.

\subsubsection{In situ ionospheric irregularity identification}

To examine topside ionospheric irregularities, the $16 \mathrm{~Hz} N_{\mathrm{e}}$ Swarm faceplate data were used. We followed the same method as Ngwira et al. (2013), Huang et al. (2014), and Aol et al. (2020) to derive the absolute electron density perturbation along Swarm orbital tracks, but we focused mainly on small-scale equatorial plasma structures. We utilized a $2 \mathrm{~s}$ running mean filter to determine the mean $N_{\mathrm{e}}$. The selected running mean is equivalent to a $15 \mathrm{~km}$ scale length, given Swarm's velocity of about $7.5 \mathrm{~km} \mathrm{~s}^{-1}$. The mean $N_{\mathrm{e}}$ was subtracted from the original observations to get the residual, $\Delta N_{\mathrm{e}}$, in a similar fashion to $\mathrm{Ngwira}$ et al. (2013), who 
obtained the residual using total electron content (TEC) data. The standard deviation of the residuals was then calculated at a running window of $2 \mathrm{~s}$ to represent the magnitude of the perturbation, $\operatorname{std}\left(\Delta N_{\mathrm{e}}\right)$. There is no standard threshold definition of how large $\operatorname{std}\left(\Delta N_{\mathrm{e}}\right)$ must be to identify plasma irregularities (Huang et al., 2014; Wan et al., 2018). However, the period considered in this study was characterized by low solar activity, and the recorded ionospheric irregularities were very weak. Therefore, a threshold value of $\operatorname{std}\left(\Delta N_{\mathrm{e}}\right)=1 \times 10^{10} \mathrm{~m}^{-3}$, similar to that adopted by Huang et al. (2014), was selected to provide a reasonable irregularity event identification at the small scales and the relatively low Swarm altitudes during the study period.

\subsubsection{Ground-based ionospheric irregularity identification}

The JULIA system computes and stores measurements of the zeroth and first lags of the autocorrelation function (ACF) of the signals from two receivers connected to the eastern and western quarters of the main antenna (Smith et al., 2015; Zhan et al., 2018). The total power, Doppler velocity at first moment, and Doppler spectral width of the scattering signals can be determined from these measurements (Hysell et al., 1997; Hysell and Burcham, 1998). Of particular interest was the SNR measurements derived by the JULIA system to check plasma plumes for a given evening. In addition, we also used the vertical plasma drift measurements made by the Jicamarca incoherent scatter radar (ISR) to examine the pre-reversal enhancement (PRE) drifts (Fejer et al., 1996; Smith et al., 2016). Field-aligned irregularities in the F region are often observed by the JULIA radar between 18:00 and 06:00 LT (Hysell and Burcham, 1998; Smith et al., 2016). Therefore, to compare the Swarm observations with the JULIA measurements, only swarm satellite passes for the time between 18:00 and 06:00 LT were considered.

The comparison of JULIA and Swarm observations was supplemented with ionosonde measurements from the JRO. The ionosonde data analysis was carried out using the SAO Explorer software (Reinisch et al., 2005). To display ionograms, both the raw and processed (SAO) data were loaded into SAO Explorer. In addition, the spread-F index QF, known as the mean spread of the diffusing F-layer trace, was obtained by the ARTIST directly from the ionograms using SAO Explorer (Galkin et al., 2008; Zhang et al., 2015), and this was also used in this study to analyse the spread-F signatures. The spread-F index QF is defined as the extent of the diffuse reflection in kilometres averaged over all frequencies where a diffuse echo appeared. For simplicity, the virtual height is used at each frequency to determine the range extent of the reflection. The ARTIST software for data analysis is described by Galkin et al. (2008). Spread-F ionograms were similarly studied by Abdu et al. (2012) using magnetically conjugate ionosondes in South America and by Zhang et al. (2015) for ionosondes and scintillation receivers at Sanya. In the following section, the results of this study are presented and discussed.

\section{Results and discussions}

\subsection{Observations of ionospheric irregularities}

Examples of equatorial ionospheric irregularity events observed by Swarm A and C on 9 March 2015 and Swarm B on 5 April 2015 are shown in Fig. 1.

In Fig. 1a, Swarm A and C encountered ionospheric irregularities along their tracks, occurring between about \pm 10 and $\pm 20^{\circ}$ quasi-dipole latitude (QLat) (Laundal and Richmond, 2016), while they orbited over the JRO on 9 March 2015. Moreover, Swarm B, which orbited at about $510 \mathrm{~km}$ altitude above sea level, recorded ionospheric irregularities on 5 April 2015, as seen from Fig. 1b. Zakharenkova et al. (2016) also observed large $N_{\mathrm{e}}$ depletions along Swarm passes using the $2 \mathrm{~Hz} N_{\mathrm{e}}$ measurements made by the LP in comparison with JULIA radar observations. With the $16 \mathrm{~Hz}$ data, $N_{\mathrm{e}}$ depletions can also be observed at even smaller scales - down to $500 \mathrm{~m}$ (Aol et al., 2020). Figure. $1 \mathrm{~b}$ presents the $\Delta N_{\mathrm{e}}$ with the background variations subtracted. Figure $1 \mathrm{c}$ shows how well the quantified absolute density perturbation captured the small-scale ionospheric irregularities in the faceplate $N_{\mathrm{e}}$ measurements. Given the fact that the ionospheric irregularities were observed in situ at Swarm altitudes, this shows that these ionospheric irregularities were in the topside ionosphere. The observed ionospheric irregularities occurred post-sunset and were most likely due to the generalized RTI (Kelley, 2009).

The coherent scatter radar observations of ionospheric plasma irregularities are often shown in range-time-intensity format in which the SNR is plotted against altitude (range) and time (Woodman and La Hoz, 1976; Hysell and Burcham, 1998). The major categories of plasma plumes that have been observed by the JULIA radar are bottom-type, bottom-side, and topside (e.g. Woodman and La Hoz, 1976; Hysell and Burcham, 1998). Examples of these categories are presented in Fig. 2a-c, which show bottom-type, bottom-side, and topside structures respectively. In Fig. 2, the observed structures are generally visible post-sunset, and this coincides with the time when the generalized RTI is expected to intensify (Kelley, 2009).

In Fig. 2a, bottom-type structures are weak and narrow scattering layers, and their thickness is less than about $50 \mathrm{~km}$. Bottom-type structures are too weak to induce prominent ionogram spread $\mathrm{F}$ or cause intense radio scintillation at very high frequency (VHF) frequencies and above (Hysell, 2000). Their disturbance in the ionosphere is also not sufficient to cause signatures on airglows (Hysell, 2000). Bottom-side structures correspond to broad, more structured, and stronger scattering layers at relatively higher altitudes that last for a few hours (as seen in Fig. 2b), whereas topside layers or radar 

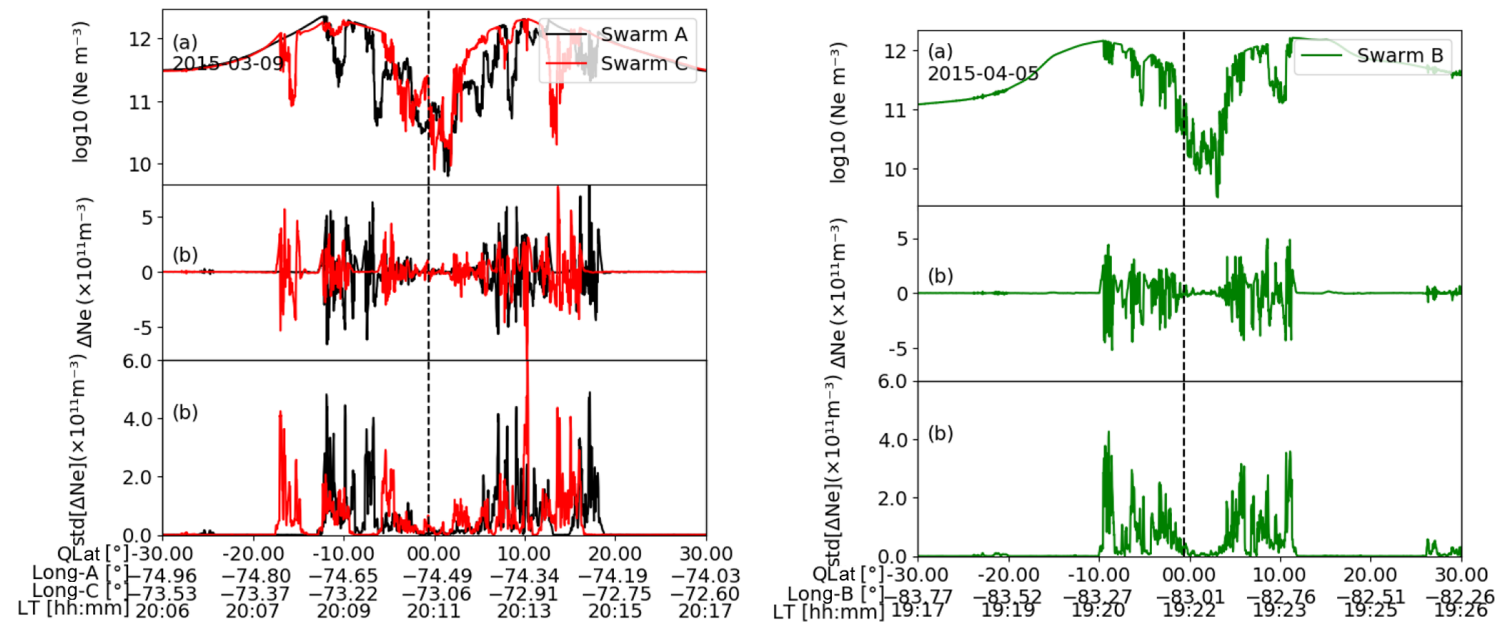

Figure 1. Swarm faceplate $N_{\mathrm{e}}$ data of ionospheric irregularity events on 9 March and 5 April 2015. The panels show (a) the $N_{\mathrm{e}}$ variation, (b) $\Delta N_{\mathrm{e}}$, and (c) $\operatorname{std}\left(\Delta N_{\mathrm{e}}\right)$ as functions of QLat, longitude (Long), and local time (LT). The dashed vertical black line represents the approximate QLat of the JRO.
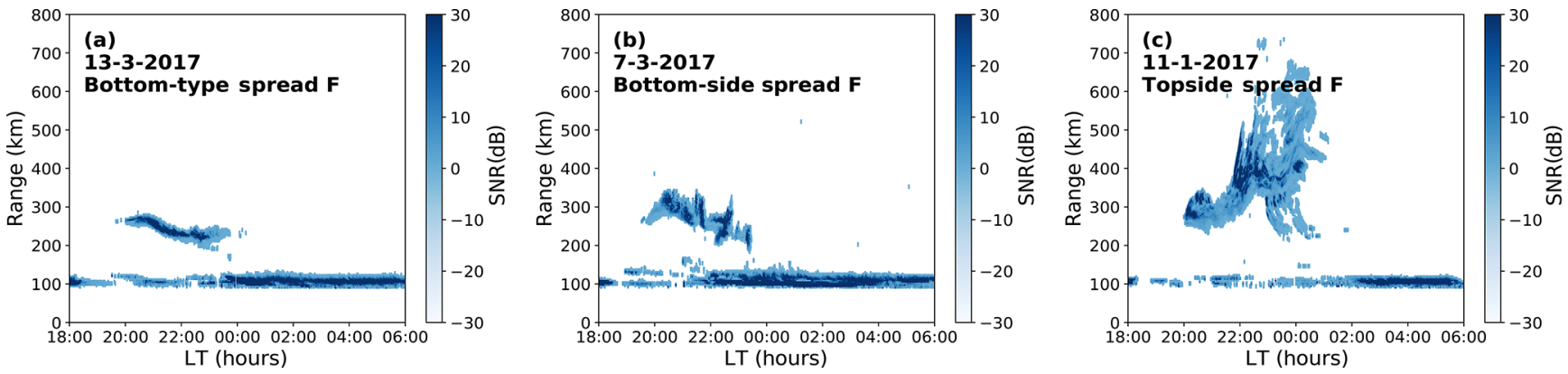

Figure 2. Examples of the different types of ESFs that may be observed by the JULIA radar. The colour bar presents the signal-to-noise ratio $(\mathrm{SNR})$ in decibels $(\mathrm{dB})$.

plumes (seen in Fig. 2c) represent larger-scale elongated structures originating from bottom-side layers and extending to the topside ionosphere (Hysell and Burcham, 1998; Hysell, 2000; Chapagain et al., 2009; Chapagain, 2011). They are indicators of strong plasma plumes (Smith et al., 2016).

To check the altitude coverage of the various types of plumes observed by the JULIA radar compared to the Swarm altitudes, a histogram of the percentage occurrence of maximum heights was generated for the different types of plumes. To determine the plume maximum height, SNR outliers were first eliminated to minimize spurious data points. The maximum height then corresponds to the maximum range in kilometres where the SNR was recorded. Figure 3 shows the frequency of occurrence of the maximum height achieved by the various types of plumes for the years from 2014 to 2018 .

In Fig. 3, the Swarm altitude range coincides with a high frequency of occurrence of the maximum range of topside plasma plumes. This reveals that the Swarm orbits are most suitable to detect topside plasma plumes compared with bottom-type and bottom-side plumes. The following subsection presents in situ observations of ionospheric irregularities by Swarm over or near the JRO longitude in comparison with the JULIA and ionosonde observations.

\subsection{Coincident ground-based and swarm observations of ionospheric irregularities}

Here, in comparison with the ground-based observations, selected Swarm orbits that were directly overhead or passed close to the JRO are presented with observed plasma density structures. Figure 4 shows example cases on 2 and 8 March 2015 where Swarm A and C passed directly over and near the JRO respectively.

Column (i) of Fig. 4 shows the range-time-intensity maps overlaid with Swarm A and C positions. The JULIA radar started to detect weak $3 \mathrm{~m}$ irregularities from an altitude of about $300 \mathrm{~km}$ at approximately 19:30 LT on 2 and 8 March 2015. Gradually, the irregularities evolved into a series of spectacular plume structures that extended to altitudes of about $800 \mathrm{~km}$. The plumes were only visible in the premidnight hours, and this corresponds to the time when the 


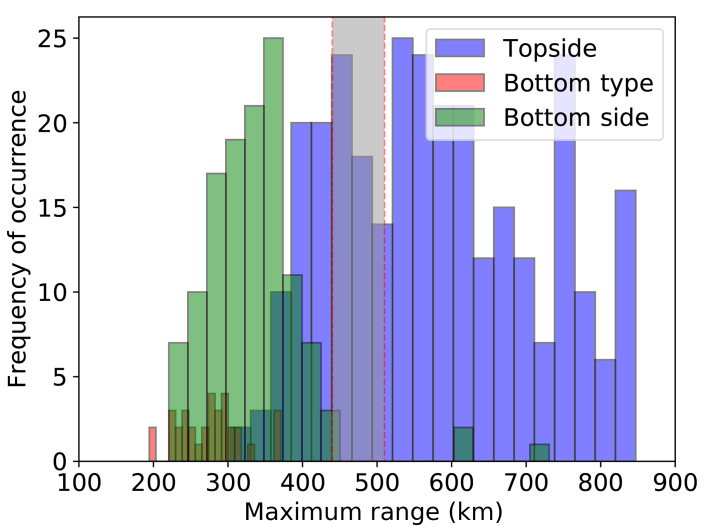

Figure 3. Frequency of occurrence of the maximum height achieved by the different types of ESFs observed by the JULIA radar for the years from 2014 to 2018 . The grey region indicates the approximate altitude coverage of the Swarm satellites from 2014 to 2018.

RTI dominates (Kelley, 2009; Schunk and Nagy, 2009). The observed plasma plumes coincided with the Swarm passes.

Columns (ii) and (iii) in Fig. 4 show that Swarm satellites encountered ionospheric irregularities along their tracks on 2 March 2015 . The irregularities were more intense near the equatorial ionization anomaly (EIA) belts at about \pm 10 to $\pm 15^{\circ} \mathrm{Q}$ Lat than at the quasi-dipole equator. $\mathrm{Za}$ kharenkova et al. (2016) analysed one sample of plasma plumes recorded by JULIA; from the results they presented, several Global Positioning System (GPS) satellites orbiting over the JRO encountered irregularities near the magnetic equator on 2 March 2015. Therefore, the structures observed by Swarm could be associated with the JULIA plasma plumes on 2 March 2015. Roddy et al. (2010) and Nishioka et al. (2011) also presented single-case events while comparing in situ plasma density measurements made by the C/NOFS satellite with JULIA observations. However, in the results presented by Roddy et al. (2010) and Nishioka et al. (2011), the EIA could not be resolved because C/NOFS orbited in a nearly meridional direction.

On 8 March 2015, Swarm A and C crossed the quasidipole equator in the evening sector at geographic longitudes of about 81.6 and $80.17^{\circ} \mathrm{W}$ respectively. The $N_{\mathrm{e}}$ profiles of Swarm A and C in columns (ii) and (iii) of Fig. 4 show depletions near the quasi-dipole equator. However, the longitudes of the Swarm satellites were offset from the JRO longitude to the west. Burke et al. (2003) made a similar observation, comparing DMSP plasma density measurements with JULIA observations. Ionospheric irregularities are generally assumed to drift westward across the magnetic field lines (Kelley, 2009). Therefore, the depletions met by Swarm A and $\mathrm{C}$ may not correspond to the plumes observed by the JULIA radar. The ionospheric irregularities observed by Swarm on 8 March 2015 may correspond to the plume remnants that drifted across the radar beam.
We also checked on the spread-F signatures on ionosonde data from JRO in comparison with the results presented in Fig. 4. Figures 5 and 6 show ionograms produced on 2 and 8 March 2015 using the SAO explorer respectively. The ionosonde measurements were recorded at $15 \mathrm{~min}$ intervals.

The sequence of ionograms presented in Fig. 5 shows that spread-F signatures were continuously observed from 00:30 to 05:00 UT (19:30 to 24:00 LT), while Swarm encountered ionospheric irregularities on 2 March 2015 between about 20:27 and 21:05 LT (see Fig. 4).

The ionograms on 8 March 2015 also showed strong spread-F signatures starting at 00:15 UT (19:15 LT) and this coincided with the time period when ionospheric irregularities and plasma plumes were recorded by Swarm and JULIA respectively. The results presented in Figs. 4, 5, and 6 show that the in situ ionospheric irregularities, spread-F signatures, and plumes were observed over and near the JRO simultaneously. Strong range spread F is caused by ionospheric irregularities and can, therefore, be regarded as a result of the generalized RTI mechanism (Rastogi et al., 1989; Wang et al., 2008; Shi et al., 2011; Alfonsi et al., 2013). The spread$\mathrm{F}$ signatures are triggered by irregularities at the bottom or within a growing plasma bubble or by declining bubbles (Abdu et al., 2012). Figures 4, 5, and 6 provide evidence that JULIA, Swarm, and the ionosonde simultaneously observed ionospheric irregularities over the JRO. In the next section, we present the results of a statistical analysis of Swarm, JULIA, and ionosonde observations.

\subsection{Statistical analysis of occurrence of ionospheric irregularities}

The formation of equatorial ionospheric irregularities is influenced by several factors including local time, season, and magnetic latitude and longitude. The data sets accumulated for the years from 2014 to 2018 were sufficient to compare the dependence of ground-based and in situ occurrence of ionospheric irregularities on various factors. Here, we present the results of the statistical analyses carried out in this study. The specific details of each statistical result are described in the following subsections.

\subsubsection{Statistics of occurrence of ionospheric irregularities by category}

The Swarm satellites regress in longitude by about $22.5^{\circ}$ between orbital ascending nodes. Therefore, in comparison with JULIA and ionosonde data, the Swarm passes were allowed to be within $\pm 5^{\circ}$ magnetic longitude of the JRO to make sure that a sufficient amount of Swarm passes could be used for the statistical examination. Both JULIA and ionosonde data during the time when Swarm was within a $\pm 5^{\circ}$ longitudinal range of the longitude of the ground site were selected. Summary plots, such as those presented in Fig. 4, were generated for all days during the years from 


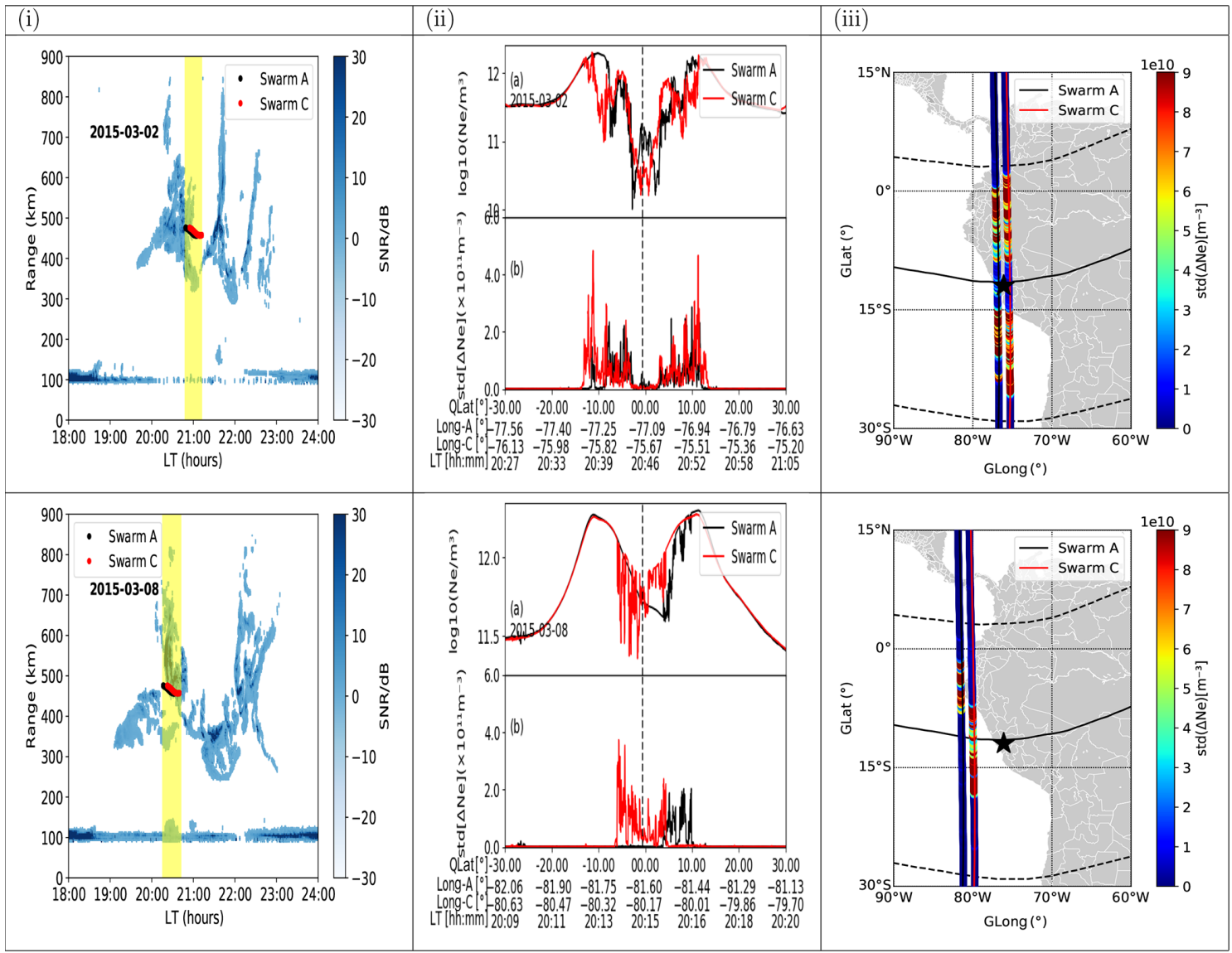

Figure 4. Examples of co-located observations by Swarm and the JULIA radar on 2 and 8 March 2015. The local time coverage and the corresponding altitude of Swarm while orbiting over or near the JRO are (black for Swarm A, and red for Swarm C) shaded yellow in column (i). The QLat of the JRO is indicated using a vertical dotted black line in column (ii). The ground tracks of Swarm and the location of the JRO are shown on the maps in column (iii). The thick black line in column (iii) shows the geomagnetic equator, and the dotted black lines show the EIA belts $\left( \pm 15^{\circ}\right.$ QLat $)$.

2014 to 2018 for which the data were available. In total, 560 night-time orbits were used for which JULIA, Swarm, and ionosonde data were concurrently available. The outputs of the summary plots could be categorized into four cases considering the presence (or absence) of irregularities. In general, these four cases are as follows: irregularities observed both on the ground and in situ, no irregularities observed on the ground or in situ, irregularities observed only in situ, and irregularities observed only on the ground. For each range-time-intensity plot, the SNR corresponding to the peak height was determined and an event was identified as a significant irregularity when the peak height was $\geq 400 \mathrm{~km}$. For a peak height less than $400 \mathrm{~km}$, the events were classified as weak irregularities or were not considered to be irregularities. It is important to note that a peak height less than $400 \mathrm{~km}$ is a representation of bottom-type, bottom-side, and no equatorial spread-F signatures; therefore, all spread-F altitudes were taken into consideration during the analysis. For the in situ Swarm observations, we considered a threshold of $1 \times 10^{10} \mathrm{~m}^{-3}$ for $\operatorname{std}\left(\Delta N_{\mathrm{e}}\right)$ as a signif- icant irregularity event, whereas $\operatorname{std}\left(\Delta N_{\mathrm{e}}\right)$ values less than the threshold were not considered to be irregularities. For the ionosonde measurements, QF values greater than or equal to $20 \mathrm{~km}$ were considered to be significant irregularity events. For each category, the percentage occurrence was computed as a ratio of the total number of events in that category to the number of observations. These cases are presented in Fig. 7a for Swarm and JULIA and in Fig. 7b for Swarm and ionosonde.

Ionospheric irregularities were detected by Swarm and JULIA in about $55.08 \%$ of the cases for Swarm A, $56.89 \%$ of the cases for Swarm C, and $58.62 \%$ of the cases for Swarm B (as seen from Fig. 7a). No ionospheric irregularities were detected by the Swarm satellites and JULIA in about $27.12 \%$ of the cases for Swarm A, 25.0\% of the cases for Swarm C, and $21.55 \%$ of the cases for Swarm B. In Fig. 7b, a high percentage occurrence was also observed when there was agreement (irregularities observed by both ionosonde and Swarm and no irregularities observed by the ionosonde and Swarm) between Swarm and ionosonde. The two categories 


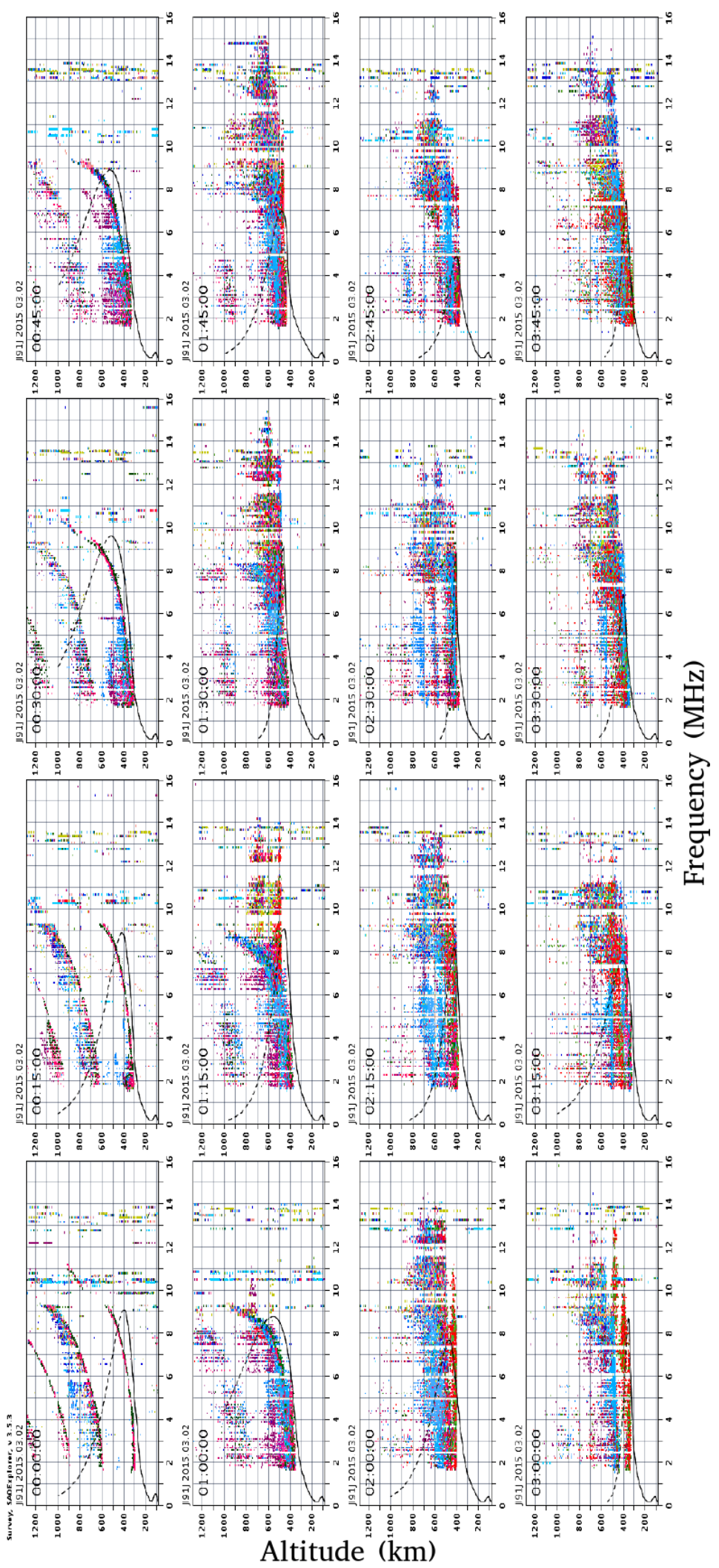

Figure 5. Ionograms showing the occurrence of ESF on 2 March 2015 between 00:15 and 03:45 UT. The local time zone of these events was UT-5. 


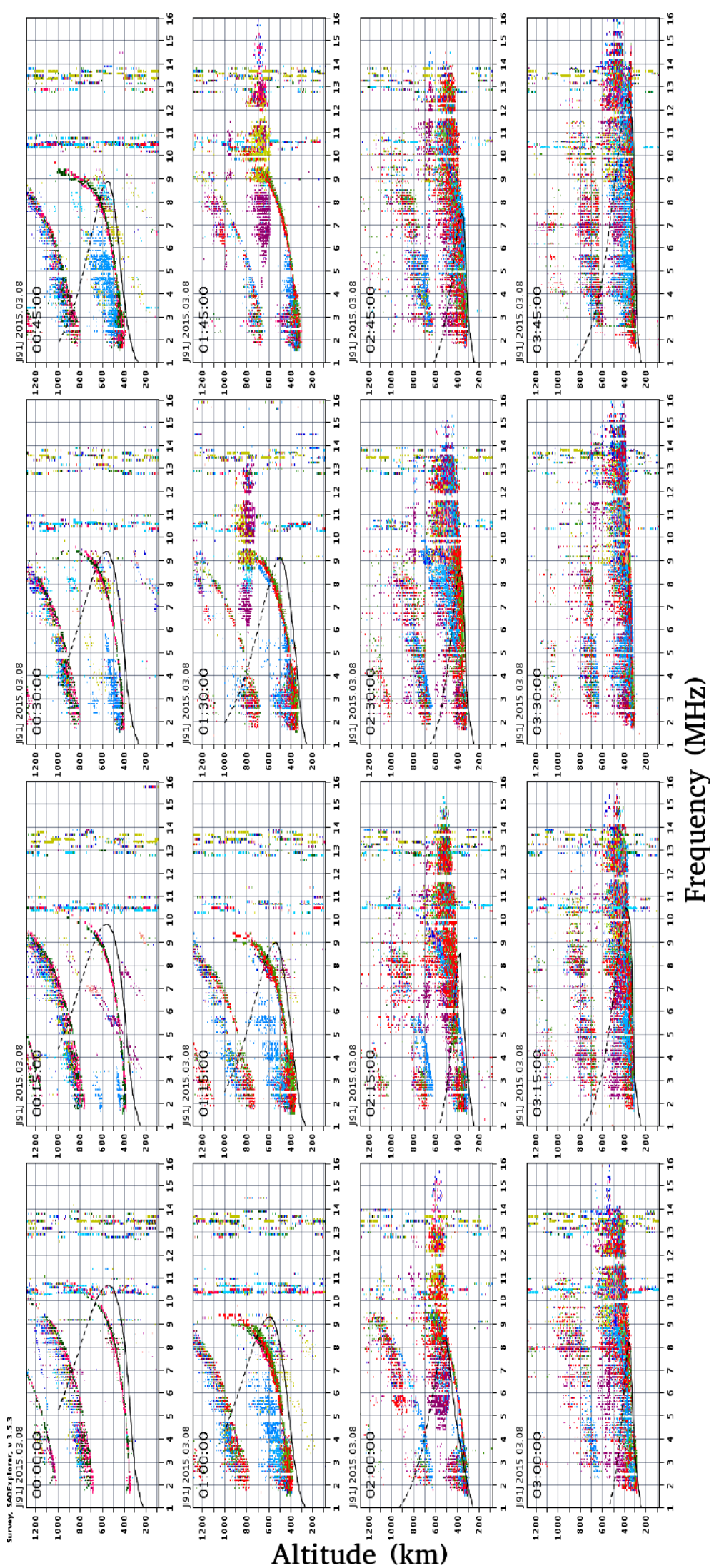

Figure 6. Ionograms showing the occurrence of ESF on 8 March 2015 between 00:15 and 03:45 UT. The local time zone of these events was UT-5. 

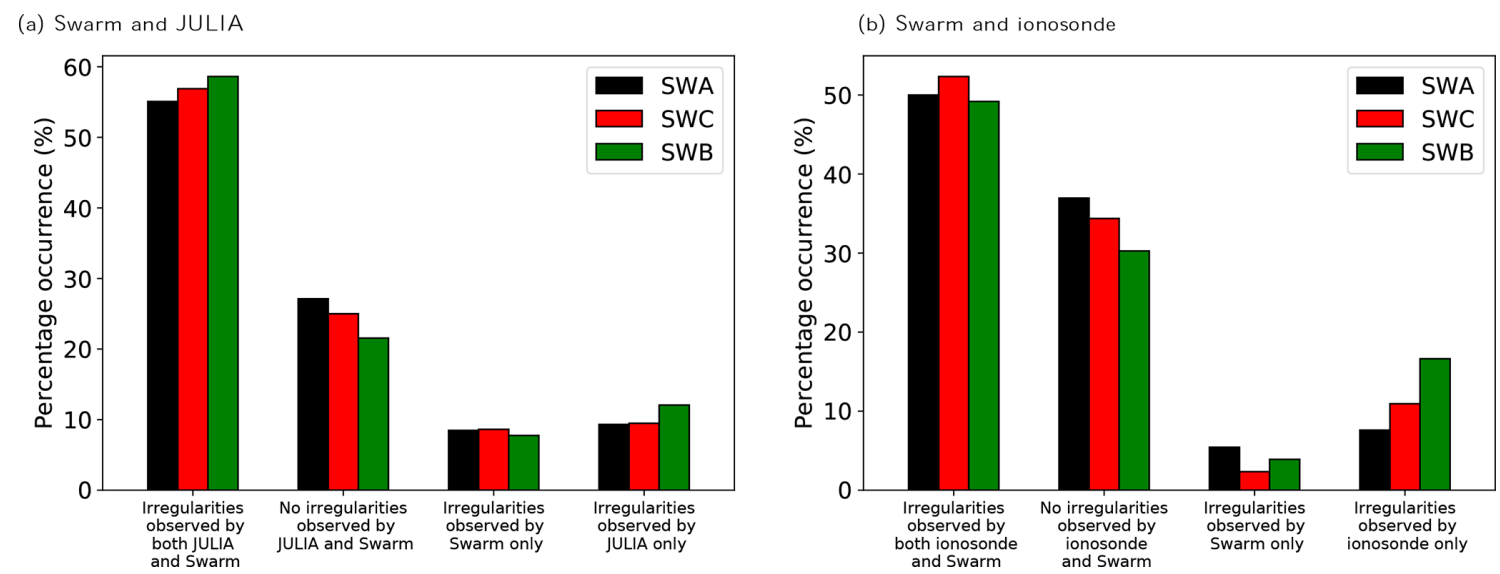

Figure 7. Percentage occurrence of irregularities in each category observed by (a) the Swarm satellites and JULIA observations and (b) the Swarm satellites and ionosonde observations for the years from 2014 to 2018.

where there was an agreement in Fig. 7a and $b$ indicate that Swarm satellites, JULIA, and the ionosonde simultaneously observed ionospheric irregularities. Burke et al. (2003) also examined the relationship between measurements from JULIA and a DMSP satellite during 110 nights for the years from 1998 to 1999. In comparison with the statistical results presented in Fig. 7 for Swarm and JULIA, the DMSP satellite sampled very few EPBs compared with plumes detected by the JULIA radar. According to Burke et al. (2003), there was a low probability that JULIA and the DMSP satellite would encounter ionospheric irregularities because most plumes could not ascend to altitudes greater than $600 \mathrm{~km}$. There were also some disagreements between the ground-based and space-based observations: JULIA and the ionosonde detected plume structures, whereas Swarm registered no events (as seen from the statistical results in Fig. 7a and b). For these cases, the Swarm altitudes during the pass were examined. It was observed that the plume structures did not ascended to Swarm altitudes by the time the satellites passed over Jicamarca or that the satellites were simply in a different location. For instances when Swarm registered events while JULIA and ionosonde recorded no signatures, we checked on the longitudinal separation between the satellite passes and the ground site. The longitudinal separations obtained between the Swarm passes and the ground site were often $\approx 5^{\circ}$, and the magnitude of the in situ perturbations were relatively low. Ionospheric irregularities tend to be magnetic field aligned (Ossakow, 1979; Kil and Heelis, 1998; Nishioka et al., 2008; Kelley, 2009); therefore, Swarm may encounter irregularities of relatively small magnitudes in situ, while JULIA and ionosonde do not identify any events, for a wider longitudinal offset of a pass from the ground site.

Zakharenkova et al. (2016) showed two cases of Swarm passes over JULIA: one case where Swarm A encountered ionospheric irregularities and JULIA recorded spread $\mathrm{F}$ and another case where Swarm B never registered an ionospheric irregularity and JULIA never recorded a spread F. The statistical results shown in Fig. 7 assert that Swarm B can also detect irregularities and plasma bubbles associated with plumes and spread $\mathrm{F}$, although with more mismatches than for Swarm A and C. Swarm B recorded more mismatches than Swarm A and C due to the progressive temporal and altitudinal separation between Swarm B and Swarm A and C (Zakharenkova et al., 2016). Swarm B orbits at a higher altitude than Swarm A and C, and it crosses the same region later than Swarm A and C. Generally, a difference in the percentage occurrence in all categories is observed between Swarm A and C (Fig. 7), although they orbit at the same altitude above sea level. The large-scale longitudinal bubble structure is sometimes observed with the Swarm A and C satellites (Xiong et al., 2016); however, for small-scale irregularities, the $1.5^{\circ}$ longitudinal separation between the satellites is too large for a significant correlation between them.

\subsubsection{Local time and seasonal variation of ionospheric irregularities}

Numerous studies have shown that ionospheric irregularities at low latitudes are a post-sunset phenomenon owing to the electrodynamics launched after sunset (e.g. Stolle et al., 2006; Lühr et al., 2014; Abdu et al., 2012). Here, we also compared the local time dependence of the occurrence of plasma plumes observed by the JULIA radar, spread $\mathrm{F}$ recorded by the ionosonde, and small-scale ionospheric irregularities encountered by Swarm for different seasons. Figure 8 shows the percentage occurrence of plasma plumes as a function of local time and height grouped into different seasons: December solstice, June solstice, March equinox, and September equinox.

To obtain the results presented in Fig. 8, ground-based JULIA SNR data for the years from 2014 to 2018 were used. To eliminate the impact of geomagnetically disturbed conditions on the statistical outcomes, the data were filtered 

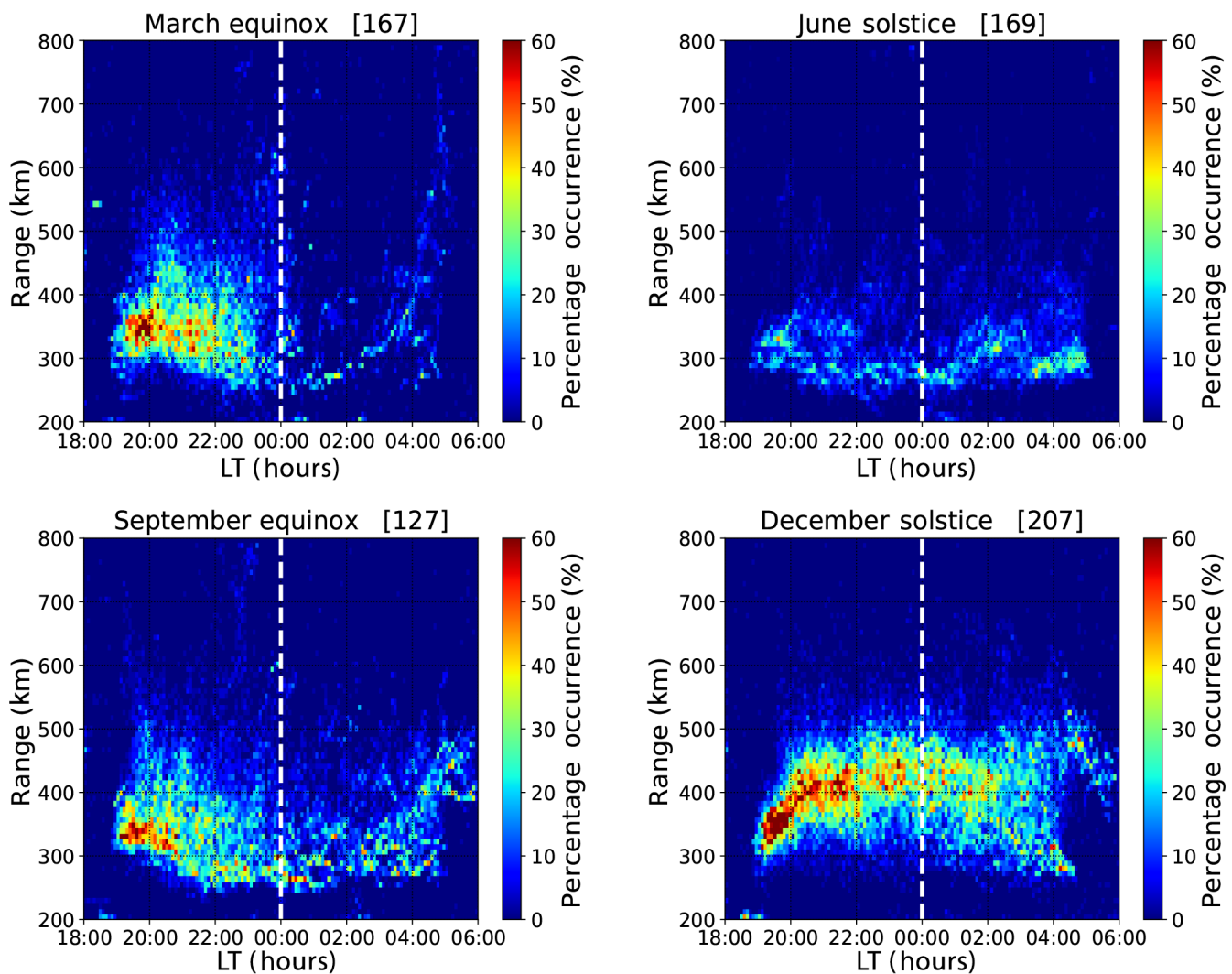

Figure 8. Percentage occurrence of plasma plumes as a function of local time and height for the years 2014-2018. Each panel represents a season. The number indicated in brackets is a count of days used to generate each season's statistics when measurements were made. The dotted white vertical line represents midnight.

and only those recorded during quiet geomagnetic conditions $(\mathrm{Kp} \leq 3)$ were taken into account. The JULIA data accumulated for the years from 2014 to 2018 were sufficient for examining the seasonal variation. Therefore, the seasonal dependence of the local time distribution of JULIA observations of ionospheric irregularities was also examined by grouping all of the data into different seasons corresponding to the March equinox (February-March-April), the June solstice (May-June-July), the September equinox (August-September-October), and the December solstice (November-December-January). For each local time-height bin, the percentage occurrence was obtained by dividing the number of observations with SNR $>10 \mathrm{~dB}$ by the total number of observations (e.g. Smith et al., 2016).

It is visible from Fig. 8 that the plasma plumes only occurred at night. Figure 8 shows the occurrence of irregularities in plasma plumes starting at about 19:00 LT that generally last past midnight. This observation is similar to those of previous studies (e.g. Kil and Heelis, 1998; Hysell and Burcham, 2002; Smith et al., 2016). The observed plasma plumes are connected with the non-linear development of the RTI, which is initiated at the bottom of the F region (Woodman and La Hoz, 1976; Huang, 2018). The highest percentage occurrence takes place at the December solstice and the equinoxes. The lowest percentage occurrence is observed at the June solstice. The daily variations in the vertical plasma drift measured by the ISR were used to better understand the seasonal patterns observed in Fig. 8. Figure 9 presents the local time variation of the F-region vertical drift velocity for the years from 2014 to 2018 .

From Fig. 9, the PRE of the vertical plasma drifts can be seen around the sunset hours (between 17:00 and 20:00 LT) before its reversal. Figure 9 shows the highest PRE peak during the December solstice and equinox seasons, whereas the PRE peak is the lowest at the June solstice. Similar observations were made by Smith et al. (2016). Comparing the results presented in Fig. 9 with the local time distributions presented in Fig. 8, it follows that a high occurrence of postsunset topside spread $\mathrm{F}$ is associated with enhancements of the PRE peak. A high PRE implies significant $\boldsymbol{E} \times \boldsymbol{B}$ vertical drifts that boost the rate of RTI growth (Sultan, 1996; Fejer et al., 1999). The PRE moves the ionospheric F layer to higher altitudes where there is less interaction between ions and neutrals. The decreased interaction between ions and neutrals leads to increased RTI (Jayachandran et al., 1993; Kelley, 2009).

Figure 8 also shows a relatively high occurrence of irregularities after midnight, especially at the solstices and the 


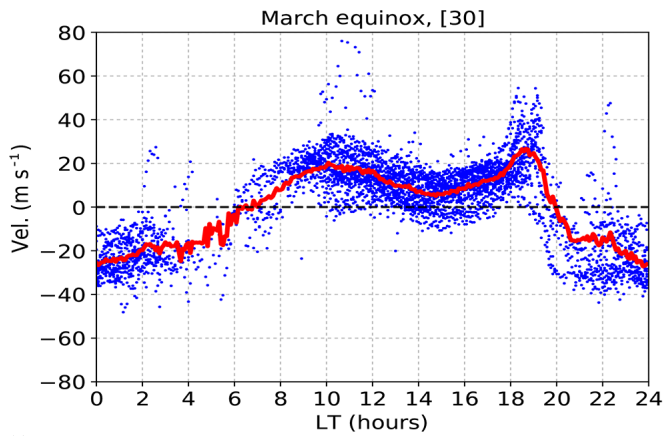

(c)

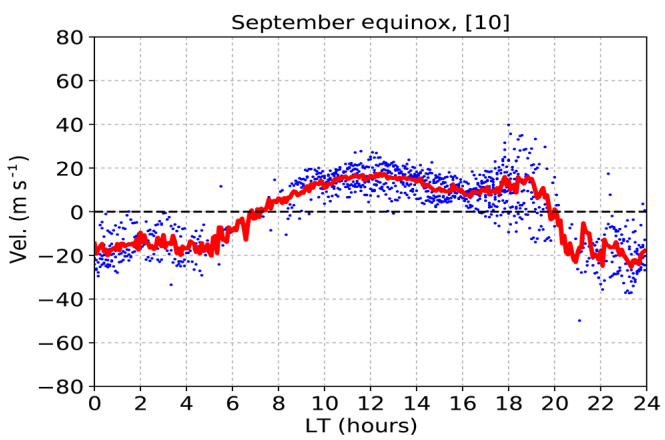

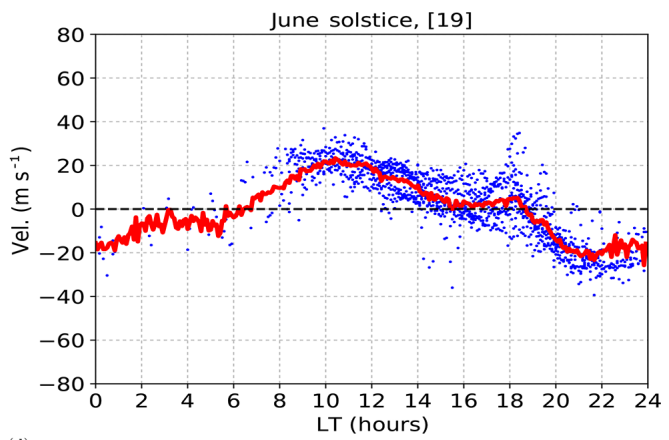

(d)

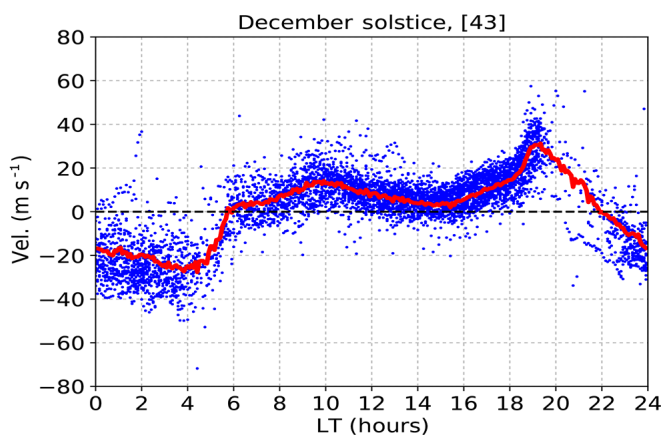

Figure 9. Local time variation of F-region vertical plasma drifts as a function of local time. The red curves represent the averaged vertical drift curves. Each panel represents a season.

September equinox. Similar observations were made by Hysell and Burcham (2002) and Smith et al. (2016). The extension of the occurrence of plumes post-midnight may be due to the late reversal time and small post-reversal electric fields (Hysell and Burcham, 2002). Despite the use of lowpower transmitters, the JULIA radar can also detect weak post-midnight irregularities, particularly during the solstice seasons (as shown in Fig. 8). However, the detected postmidnight ionospheric irregularities often exist at much lower altitudes than those presented by Smith et al. (2016). Using Jicamarca radar measurements, Fejer et al. (1999) reported that the ionospheric irregularities that occur after midnight are typically well-formed structures that can be connected to the disturbed dynamo.

Figure 10 shows the QF indices derived from ionosonde observations as a function of local time and month. To obtain the results presented in Fig. 10, ground-based ionosonde data for the years from 2014 to 2018 were used. These data were also filtered, and only those recorded during quiet geomagnetic conditions $(\mathrm{Kp} \leq 3)$ were considered.

Considering that equatorial ionospheric irregularities are night-time phenomena, we only present $\mathrm{QF}$ data from 18:00 to 06:00 LT in Fig. 10. To generate Fig. 10, the QF data were averaged over $0.1 \mathrm{~h}$ local time bins for each month ( $y$ axis). Figure 10 shows that the $\mathrm{QF}$ index was high in the post-sunset period with peak values occurring between about 20:00 and 00:00 LT at the December solstice and the

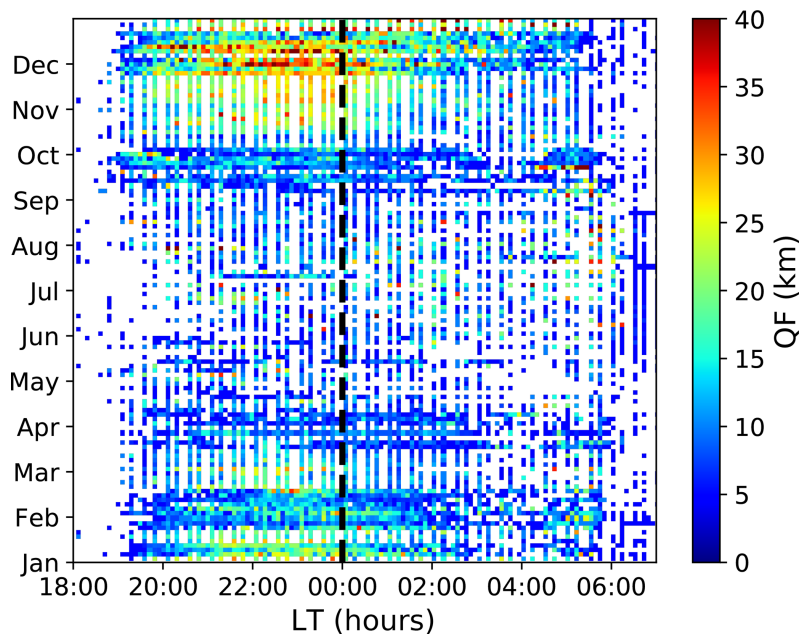

Figure 10. Month and local time (LT) variations of QF indices observed over the JRO for the years from 2014 to 2018. The white spaces show periods when no spread $\mathrm{F}$ was detected. The dotted black vertical line represents midnight.

equinoxes. The high $\mathrm{QF}$ values at the equinoxes and the December solstice are most likely due to the RTI, which is usually triggered at the bottom side of a rising equatorial $\mathrm{F}$ layer. The rate of growth of the RTI depends on the meridional wind and the eastward electric field PRE determined by the 
longitudinal gradient of the flux-tube-integrated conductivity (Sultan, 1996; Basu, 2002). At the June solstice, the QF values were small after sunset, as seen in Fig. 10. Generally, Fig. 10 shows moderate QF values lasting until local midnight or longer (similar to the trend presented in Fig. 8). The low post-sunset QF values at the June solstice can be attributed to the small PRE, which can also be seen in Fig. 9c.

Figure 11 shows the QLat-LT distributions of $\operatorname{std}\left(\Delta N_{\mathrm{e}}\right)$ for the Swarm satellites for the years from 2014 to 2018 . Recall that the Swarm passes were allowed to be within $\pm 5^{\circ}$ magnetic longitude. The $N_{\mathrm{e}}$ data collected for the 5 years were also grouped into different seasons similar to those presented in Fig. 8. The results presented in Fig. 11 were also generated considering only the geomagnetically quiet conditions $(\mathrm{Kp} \leq 3)$. The $\operatorname{std}\left(\Delta N_{\mathrm{e}}\right)$ was then calculated in bins of $1^{\circ} \times 0.1 \mathrm{~h}$ resolution in QLat and local time. The occurrence rate of ionospheric irregularities does not always correspond to the highest amplitude of ionospheric irregularities (Wan et al., 2018). Therefore, we presented the calculated $\operatorname{std}\left(\Delta N_{\mathrm{e}}\right)$ per bin as a function of QLat and local time, as seen in Fig. 11. From Fig. 11, high $\operatorname{std}\left(\Delta N_{\mathrm{e}}\right)$ values frequently occurred between about \pm 10 and $\pm 20^{\circ}$ QLat, i.e. at the approximate location of the EIA belts. The distribution of the $\operatorname{std}\left(\Delta N_{\mathrm{e}}\right)$, as seen in Fig. 11, is essentially symmetrical about the quasi-dipole equator. The symmetrical distribution about the magnetic equator has also been observed in earlier studies (e.g. Stolle et al., 2006; Carter et al., 2013; Wan et al., 2018); this confirms that equatorial ionospheric irregularities usually extend along the magnetic field lines in the northern and southern directions, and they are concentrated at the EIA belts (Kelley, 2009). The $\operatorname{std}\left(\Delta N_{\mathrm{e}}\right)$ attained a maximum between 20:00 and 22:00 LT. A decrease was detected after 22:00 until 06:00 LT. The local time distribution of $\operatorname{std}\left(\Delta N_{\mathrm{e}}\right)$ for Swarm A, B, and C is the same as that of the quiet-time F-region echoes presented in Fig. 8 and the QF distribution presented in Fig. 10. The distribution of $\operatorname{std}\left(\Delta N_{\mathrm{e}}\right)$ shown in Fig. 11 has peak values at local times and QLat ranges where the RTI is expected. In terms of seasons, as observed from Fig. 11, high values of $\operatorname{std}\left(\Delta N_{\mathrm{e}}\right)$ were seen at the equinoxes and the December solstice, whereas the lowest values were detected at the June solstice. This is similar to the seasonal dependence of quiettime F-region echoes presented in Fig. 8. In Fig. 11, Swarm hardly encountered post-midnight irregularities while orbiting over South America during all seasons. In Fig. 8, it is observed that the post-midnight plumes often existed at lower altitudes at the solstices and the September equinox. Therefore, the low post-midnight ionospheric irregularity observations by Swarm may be because the plumes failed to reach Swarm altitudes.

For comparison, Fig. 12 shows the quasi-dipole versus local time distribution of ionospheric irregularities based on the Swarm Ionospheric Bubble Index (IBI), which is a standard Level 2 product of the Swarm mission (Park et al., 2013). The IBI provides information on the climatology of ionospheric irregularities and the level of magnetic field disturbance by taking both the electron density and magnetic field measurements into account (Park et al., 2013; Wan et al., 2018). It is important to note that the IBI is has a value of 1,0 , or -1 for bubble detected, not detected, or undetermined respectively. Therefore, to generate the results in Fig. 12, the data sets were first grouped into different seasons corresponding to the March equinox, the June solstice, the September equinox, and the December solstice. For each season, the data were then binned into $1^{\circ} \times 0.1 \mathrm{~h}$ quasi-dipole latitude-local time bins. For each quasi-dipole latitude-local time bin, the percentage occurrence was obtained by dividing the number of observations with an IBI of 1 by the total number of observations. The binned percentage occurrence of an IBI of 1 shown in Fig. 12 has similar seasonal characteristics as the in situ irregularities shown in Fig. 11. The percentage occurrence of an IBI of 1 ranges from $0 \%$ to $20 \%$ which is relatively low. The low percentage occurrence of ionospheric irregularities derived from the IBI was also observed by Wan et al. (2018). This may be because the magnitude of ionospheric irregularities must be large enough to cause magnetic field fluctuations (Wan et al., 2018). The latitudinal profile of $\operatorname{std}\left(\Delta N_{\mathrm{e}}\right)$ and the percentage occurrence of an IBI of 1 have peaks near the anomaly crests (about $\pm 15^{\circ}$ QLat). The diamagnetic effect in fluctuations of $N_{\mathrm{e}}$ are believed to be the cause of an IBI of 1, and this occurs at the anomaly crests (Stolle et al., 2006; Lühr et al., 2003).

The Bragg condition for the JULIA radar implies that the coherent spread echoes are from density variations at about a $3 \mathrm{~m}$ wavelength (Kelley, 2009). The Bragg condition for backscatter means that a radar can only observe structures in the refractive index with a size close to the half radar wavelength (Kelley, 2009; Hocking et al., 2016). The Swarm electron density measurements used in this study are limited by a sampling rate of $16 \mathrm{~Hz}$ and an orbital velocity of about $7.5 \mathrm{~km} \mathrm{~s}^{-1}$ to wavelengths of about $500 \mathrm{~m}$ and longer respectively. The good correlation between the Swarm measurements at these wavelengths and the spread echoes from Swarm altitudes suggest that the irregularities seen by Swarm occur over a spectrum of different wavelengths, at least from about $500 \mathrm{~m}$ down to the radar wavelength of $3 \mathrm{~m}$. A nonlinear decay of unstable waves could explain this. In addition, we expect that the radar signal could be affected by scintillations which are particularly known from one-way signal propagation such as in Global Navigation Satellite System (GNSS) and VHF satellite beacons (Burke et al., 2003; Zuo et al., 2016). For the radar, this could be relevant for echoes where the Bragg reflection occurs at high altitudes, above Swarm. Fresnel theory shows that wavelengths at the Fresnel scale of $\sqrt{(2 \lambda d)}$ are most relevant for causing scintillations. Here, $\lambda$ is the wavelength ( $3 \mathrm{~m}$ for the JULIA radar), and $d$ is the distance from the perturbation to the receiver (445$510 \mathrm{~km}$ for Swarm). This gives a Fresnel scale between about 1.6 and $1.7 \mathrm{~km}$. The Swarm measurements generally indicate that irregularities at such scales are present near the paths 
(a) Swarm A
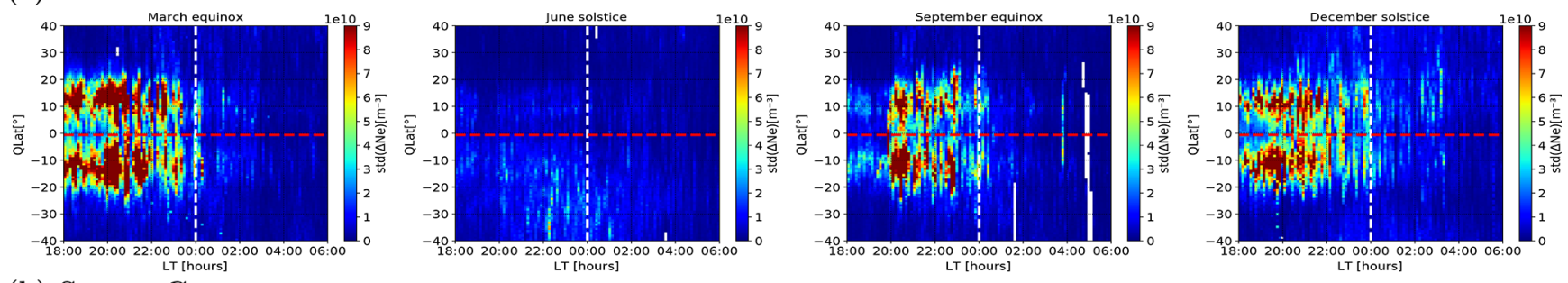

(b) Swarm C
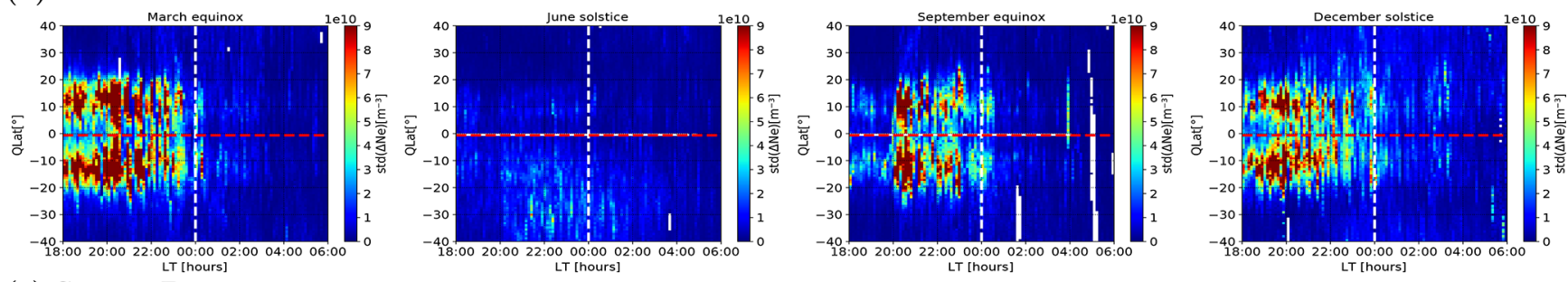

(c) Swarm B
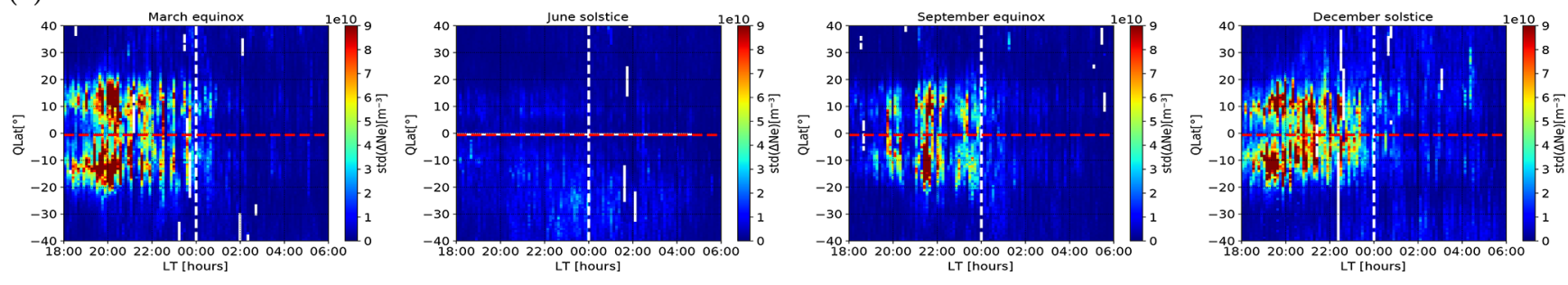

Figure 11. Quasi-dipole latitude and local time distributions of $\operatorname{std}\left(\Delta N_{\mathrm{e}}\right)$ for Swarm A, C, and B for the years from 2014 to 2018 . The dotted white vertical line represents midnight, and the dotted red horizontal line represents the quasi-dipole latitude of Jicamarca $\left(\approx-0.6^{\circ}\right)$. The white spaces represent data gaps.

of Bragg-reflected radar signals. Therefore, we suggest that spread-F signals may, at times, be a result of both the Bragg backscattering at the highest altitude and scintillations of the radio waves to and from the scatter region.

\section{Conclusions}

In this paper, the results of a study of equatorial ionospheric irregularities detected by the JULIA radar and ionosonde in comparison with in situ $N_{\mathrm{e}}$ measurements made by Swarm for the years from 2014 to 2018 was presented. Cases of coincidence between Swarm, JULIA, and ionosonde observations were discussed. Moreover, the JULIA, ionosonde, and Swarm observations were examined statistically during geomagnetically quiet conditions. The local time and seasonal statistical patterns obtained from JULIA, the ionosonde, and Swarm were explained using drift measurements by the ISR.

Results based on the JULIA radar and the ionosonde agreed with the plasma density obtained from measurements of the Swarm faceplate for single satellite passes over or near the JRO. Based on an on-off classification, in the majority of cases, when the JULIA radar detected topside plasma plumes, Swarm also observed plasma bubbles when its trajectory crossed directly overhead or near the JRO. This was also true for the ionosonde measurements. A few exceptions were also observed when the JULIA radar and the ionosonde detected the presence of plasma structures, whereas Swarm did not record any bubbles and vice versa. For the case when JULIA and the ionosonde recorded irregularity signatures whereas Swarm observed no structures, the plume structures may not have ascended to Swarm altitudes by the time the satellites passed over Jicamarca or the satellites may simply have been in a different location. Swarm was able to detect ionospheric irregularities in situ, whereas no signature was recorded on the ground simply because the irregularities occurred at magnetic longitudes that were largely offset from the longitude of the ground site. Statistical differences between Swarm A and C were observed, and these were attributed to the $1.5^{\circ}$ longitudinal separation between them which becomes significant for small-scale irregularities.

The three phenomena, namely plasma plumes observed by the JULIA radar, spread-F signatures recorded by the ionosonde, and small-scale irregularities detected by Swarm, revealed similarities in the patterns of occurrence based on the local time and different seasons. The highest occurrence rate was observed at the December solstice and at the equinoxes, whereas a low occurrence rate was observed at the June solstice. Measurements of the vertical plasma drift, made by the ISR, were used to understand the seasonal de- 
(a) Swarm A
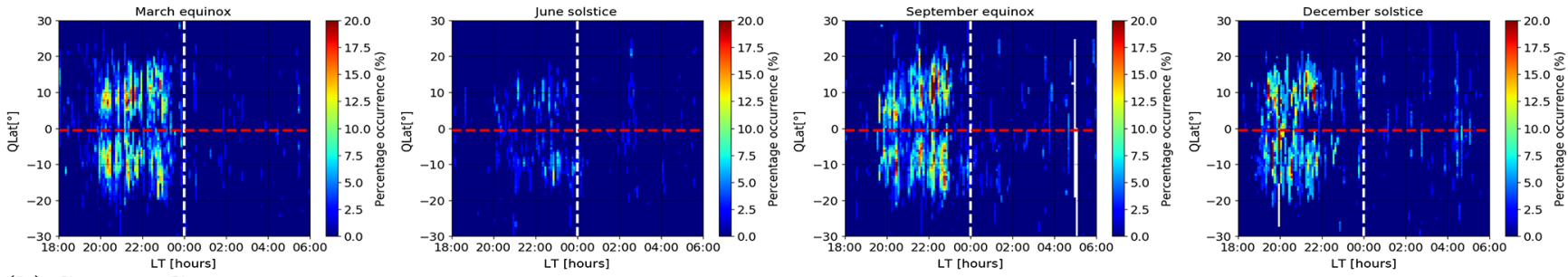

(b) Swarm C
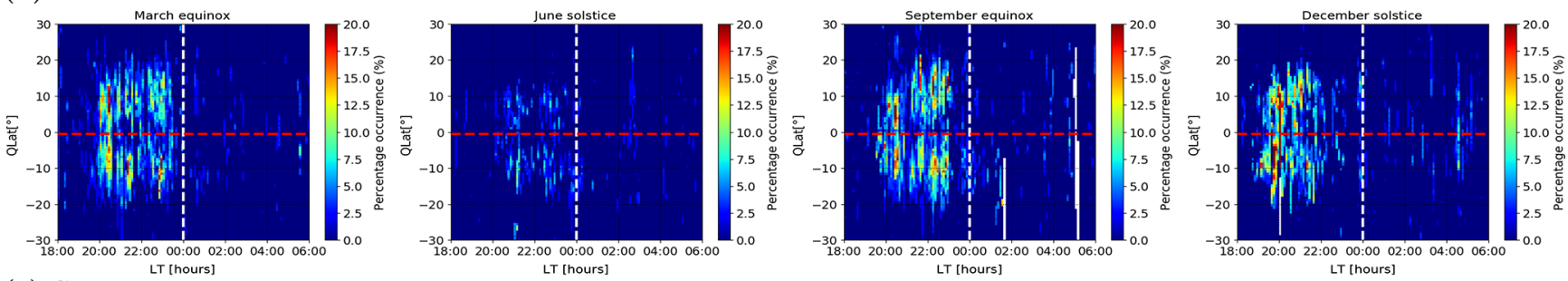

(c) Swarm B
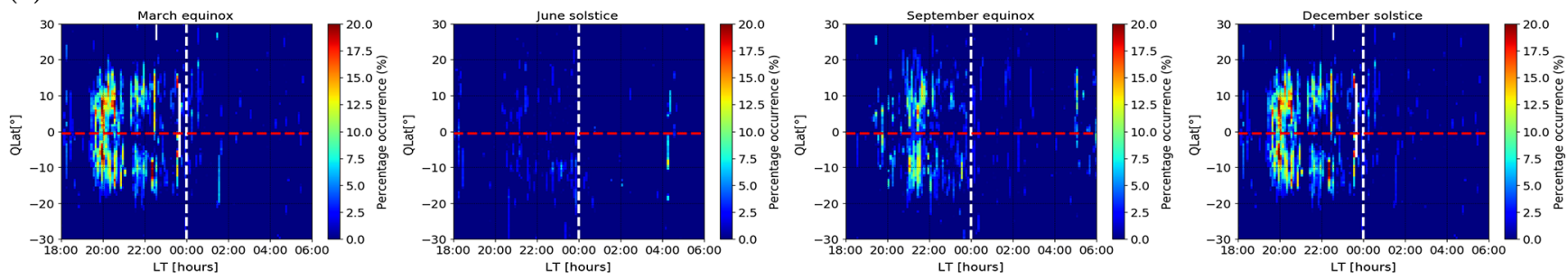

Figure 12. Quasi-dipole latitude and local time distributions of the IBI for Swarm A, C, and B for the years from 2014 to 2018 . The dotted white vertical line represents midnight, and the dotted red horizontal line represents the quasi-dipole latitude of Jicamarca $\left(\approx-0.6^{\circ}\right)$. The white spaces represent data gaps.

pendence of the occurrence of topside spread $\mathrm{F}$ and in situ density irregularities. The seasonal dependence of the occurrence of topside spread $\mathrm{F}$ and in situ $N_{\mathrm{e}}$ irregularities can be explained by the extent to which plasma is drifted vertically upwards.

The 5 year Swarm faceplate $N_{\mathrm{e}}$ data set has revealed a lot of detailed features regarding the electron density variations associated with plasma bubbles. In situ measurements of $N_{\mathrm{e}}$ by Swarm are a promising tool to indicate the likelihood of plasma plumes and spread-F occurrence at times and locations where radar or ionosonde measurements are not available. The geometry, however, is an important factor; therefore, when determining whether satellite observations are valid or accurate for any given ground site, algorithms should take the position of the satellite and the apex height of the magnetic field lines into account.

Data availability. The official Swarm website is http://earth.esa. int/swarm (last access: 30 September 2020, ESA Earth Observations, 2020), and ftp://swarm-diss.eo.esa.int (last access: 30 September 2020, IRF, 2020a) is the server for the distribution of Swarm data. The IBI measurements used in this study can be obtained from https://swarm-diss.eo.esa.int/ \#swarm\%2FLevel2daily\%2FLatest_baselines\%2FIBI (last access:
30 September 2020, IRF, 2020b). The radar measurements used in this study can be obtained from the Madrigal database at http: //jro.igp.gob.pe/madrigal/ (last access: 30 September 2020, Jicamarca Radio Observatory, 2020). The Kp index values used in this study were obtained from http://omniweb.gsfc.nasa.gov/ (last access: 30 September 2020, Space Physics Data Facility, 2020). The SAO Explorer software was obtained from http://ulcar.uml.edu/ SAO-X/SAO-X.html (last access: 30 September 2020, UMLCAR, 2020).

Author contributions. The ideas presented in this paper were designed and implemented by AS, SB, EJ, and MM. AS prepared the paper with contributions from all the co-authors.

Competing interests. The authors declare that they have no conflict of interest.

Acknowledgements. This study was financially supported by the International Science Programme (ISP) of the Uppsala University, Sweden, and by the Jicamarca International Research Experience Program (JIREP, http://www.igp.gob.pe/convocatorias/jirep) of the Instituto Geofísico del Perú with support from the US National Science Foundation (NSF). The authors acknowledge the European 
Space Agency's Swarm team for the Swarm mission. We also acknowledge the anonymous referees for their insightful comments which significantly improved the quality of this paper.

Financial support. This research has been supported by the International Science Programme of the Uppsala University, Sweden (grant no. UGA 02) and the Jicamarca International Research Experience Program (NSF grant no. AGS-1732209).

Review statement. This paper was edited by Keisuke Hosokawa and reviewed by two anonymous referees.

\section{References}

Aa, E., Zou, S., Ridley, A., Zhang, S., Coster, A. J., Erickson, P. J., Liu, S., and Ren, J.: Merging of Storm Time Midlatitude Traveling Ionospheric Disturbances and Equatorial Plasma Bubbles, Space Weather, 17, 285-298, https://doi.org/10.1029/2018sw002101, 2019.

Aa, E., Zou, S., Eastes, R., Karan, D. K., Zhang, S.-R., Erickson, P. J., and Coster, A. J.: Coordinated GroundBased and Space-Based Observations of Equatorial Plasma Bubbles, J. Geophys. Res., 125, e2019JA027569, https://doi.org/10.1029/2019ja027569, 2020.

Abdu, M. A.: Outstanding problems in the equatorial ionospherethermosphere electrodynamics relevant to spread F, J. Atmos. Sol.-Terr. Phy., 63, 869-884, https://doi.org/10.1016/S13646826(00)00201-7, 2001.

Abdu, M. A., Batista, I. S., Reinisch, B. W., MacDougall, J. W., Kherani, E. A., and Sobral, J. H. A.: Equatorial range spread F echoes from coherent backscatter, and irregularity growth processes, from conjugate point digital ionograms, Radio Sci., 47, RS6003, https://doi.org/10.1029/2012rs005002, 2012.

Alfonsi, L., Spogli, L., Pezzopane, M., Romano, V., Zuccheretti, E., Franceschi, G. D., Cabrera, M. A., and Ezquer, R. G.: Comparative analysis of spread-F signature and GPS scintillation occurrences at Tucumán, Argentina, J. Geophys. Res., 118, 44834502, https://doi.org/10.1002/jgra.50378, 2013.

Aol, S., Buchert, S., and Jurua, E.: Traits of sub-kilometre F-region irregularities as seen with the Swarm satellites, Ann. Geophys., 38, 243-261, https://doi.org/10.5194/angeo-38-243-2020, 2020.

Basu, B.: On the linear theory of equatorial plasma instability: Comparison of different descriptions, J. Geophys. Res., 107, 1199, https://doi.org/10.1029/2001JA000317, 2002.

Basu, S., McClure, J. P., Basu, S., Hanson, W. B., and Aarons, J.: Coordinated study of equatorial scintillation and in situ and radar observations of nighttime $F$ region irregularities, J. Geophys. Res., 85, 5119-5130, https://doi.org/10.1029/JA085iA10p05119, 1980.

Booker, H. G. and Wells, H. W.: Scattering of radio waves by the F-region of the ionosphere, J. Geophys. Res., 43, 249, https://doi.org/10.1029/te043i003p00249, 1938.

Buchert, S.: Extended EFI LP data FP release notes, ESA Technical Note, available at: ftp://swarm-diss.eo.esa.int/Advanced/ Plasma_Data/16_Hz_Faceplate_plasma_density (last access: 30 September 2020), 2016.
Burke, W. J., Huang, C. Y., Valladares, C. E., Machuzak, J. S., Gentile, L. C., and Sultan, P. J.: Multipoint observations of equatorial plasma bubbles, J. Geophys. Res., 108, 1221, https://doi.org/10.1029/2002JA009382, 2003.

Burke, W. J., Gentile, L. C., Huang, C. Y., Valladares, C. E., and $\mathrm{Su}, \mathrm{S}$. Y.: Longitudinal variability of equatorial plasma bubbles observed by DMSP and ROCSAT-1, J. Geophys. Res., 109, A12301, https://doi.org/10.1029/2004JA010583, 2004.

Carter, B. A., Zhang, K., Norman, R., Kumar, V. V., and Kumar, S.: On the occurrence of equatorial F-region irregularities during solar minimum using radio occultation measurements, J. Geophys Res., 118, 892-904, https://doi.org/10.1002/jgra.50089, 2013.

Chapagain, N.: Dynamics of Equatorial Spread F Using GroundBased Optical and Radar Measurements (Dissertation for the degree of Doctor of Philosophy in Physics), Utah State University, United States, available at: https://repositorio.igp.gob.pe/handle/ IGP/4468 (last access: 30 September 2020), 202 pp., 2011.

Chapagain, N. P., Fejer, B. G., and Chau, J. L.: Climatology of postsunset equatorial spread F over Jicamarca, J. Geophys. Res., 114, A07307, https://doi.org/10.1029/2008JA013911, 2009.

Cherniak, I., Zakharenkova, I., and Sokolovsky, S.: MultiInstrumental Observation of Storm-Induced Ionospheric Plasma Bubbles at Equatorial and Middle Latitudes, J. Geophys. Res., 124, 1491-1508, https://doi.org/10.1029/2018ja026309, 2019.

ESA Earth Observations: available at: http://earth.esa.int/swarm, last access: 30 September 2020.

Fejer, B. G., de Paula, E. R., Scherliess, L., and Batista, I. S.: Incoherent scatter radar, ionosonde, and satellite measurements of equatorialFregion vertical plasma drifts in the evening sector, Geophys. Res. Lett., 23, 1733-1736, https://doi.org/10.1029/96g101847, 1996.

Fejer, B. G., Scherliess, L., and de Paula, E. R.: Effects of the vertical plasma drift velocity on the generation and evolution of equatorial spreadF, J. Geophys. Res., 104, 19859-19869, https://doi.org/10.1029/1999ja900271, 1999.

Friis-Christensen, E., Lühr, H., and Hulot, G.: Swarm: A constellation to study the Earth's magnetic field, Earth Planets Space, 58, 351-358, 2006.

Galkin, I. A., Khmyrov, G. M., Kozlov, A. V., Reinisch, B. W., Huang, X., Paznukhov, V. V., Song, P., Foster, J., Mendillo, M., and Bilitza, D.: The ARTIST 5, in: AIP Conference Proceedings, AIP, https://doi.org/10.1063/1.2885024, 2008.

Hickey, D. A., Martinis, C. R., Mendillo, M., Baumgardner, J., Wroten, J., and Milla, M.: Simultaneous $6300 \AA$ airglow and radar observations of ionospheric irregularities and dynamics at the geomagnetic equator, Ann. Geophys., 36, 473-487, https://doi.org/10.5194/angeo-36-473-2018, 2018.

Hocking, W. K., Röttger, J., Palmer, R. D., Sato, T., and Chilson, P. B.: Atmospheric radar: Application and science of MST radars in the Earth's mesosphere, stratosphere, troposphere, and weakly ionized regions, Cambridge University Press, 855 pp., 2016.

Huang, C.-S.: Effects of the postsunset vertical plasma drift on the generation of equatorial spread F, Prog. Earth Planet. Sci., 5, https://doi.org/10.1186/s40645-017-0155-4, 2018.

Huang, C.-S., La Beaujardiere, O., Roddy, P., Hunton, D., Liu, J., and Chen, S.: Occurrence probability and amplitude of equatorial ionospheric irregularities associated with plasma bubbles during low and moderate solar activities (2008-2012), J. Geophys. Res., 119, 1186-1199, https://doi.org/10.1002/2013ja019212, 2014. 
Hysell, D. L.: An overview and synthesis of plasma irregularities in equatorial spread/F, J. Atmos. Sol.-Terr. Phy., 62, 1037-1056, https://doi.org/10.1016/S1364-6826(00)00095-X, 2000.

Hysell, D. L. and Burcham, J. D.: JULIA radar studies of equatorial spread F, J. Geophys. Res., 103, 29155-29168, https://doi.org/10.1029/98JA02655, 1998.

Hysell, D. L. and Burcham, J. D.: Long term studies of equatorial spread/F using the JULIA radar at Jicamarca, J. Atmos. Sol.-Terr. Phy., 64, 1531-1543, https://doi.org/10.1016/S13646826(02)00091-3, 2002.

Hysell, D. L., Larsen, M. F., and Woodman, R. F.: JULIA radar studies of electric fields in the equatorial electrojet, Geophys. Res. Lett., 24, 1687-1690, https://doi.org/10.1029/97GL00373, 1997.

Hysell, D. L., Hedden, R. B., Chau, J. L., Galindo, F. R., Roddy, P. A., and Pfaff, R. F.: Comparing F region ionospheric irregularity observations from C/NOFS and Jicamarca, J. Geophys. Res., 36, L00C01, https://doi.org/10.1029/2009GL038983, 2009.

IRF: available at: ftp://swarm-diss.eo.esa.int, last access: 30 September 2020a.

IRF: available at: https://swarm-diss.eo.esa.int/\#swarm\% 2FLevel2daily\%2FLatest_baselines\%2FIBI, last access: 30 September 2020 b.

Jayachandran, B., Balan, N., Rao, P. B., Sastri, J. H., and Bailey, G. J.: HF Doppler and ionosonde observations on the onset conditions of equatorial spread F, Geophys. Res. Lett., 98, 13, https://doi.org/10.1029/93JA00302, 1993.

Jicamarca Radio Observatory: available at: http://jro.igp.gob.pe/ madrigal/, last access: 30 September 2020.

Kelley, M. C., The Earth's Ionosphere, International Geophysics, Elsevier, Ithaca, NY, USA, 2009.

Kelley, M. C., Rodrigues, F. S., Makela, J. J., Tsunoda, R., Roddy, P. A., Hunton, D. E., Retterer, J. M., de La Beaujardiere, O., de Paula, E. R., and Ilma, R. R.: C/NOFS and radar observations during a convective ionospheric storm event over South America, Geophys. Res. Lett., 36, L00C07, https://doi.org/10.1029/2009GL039378, 2009.

Kil, H. and Heelis, R. A.: Global distribution of density irregularities in the equatorial ionosphere, J. Geophys. Res., 103, 407-418, https://doi.org/10.1029/97JA02698, 1998.

Kil, H., Paxton, L. J., and Oh, S.-J.: Global bubble distribution seen from ROCSAT-1 and its association with the evening prereversal enhancement, J. Geophys. Res., 114, A06307, https://doi.org/10.1029/2008ja013672, 2009.

Knudsen, D. J., Burchill, J. K., Buchert, S. C., Eriksson, A. I., Gill, R., Wahlund, J.-E., Åhlen, L., Smith, M., and Moffat, B.: Thermal ion imagers and Langmuir probes in the Swarm electric field instruments, J. Geophys. Res., 2655-2673, https://doi.org/10.1002/2016ja022571, 2017.

Laundal, K. M. and Richmond, A. D.: Magnetic Coordinate Systems, Space Science Reviews, 206, 27-59, https://doi.org/10.1007/s11214-016-0275-y, 2016.

Lühr, H., Rother, M., Maus, S., Mai, W., and Cooke, D.: The diamagnetic effect of the equatorial Appleton anomaly: Its characteristics and impact on geomagnetic field modeling, Geophys. Res. Lett., 30, 1906, https://doi.org/10.1029/2003gl017407, 2003.

Lühr, H., Xiong, C., Park, J., and Rauberg, J.: Systematic study of intermediate-scale structures of equatorial plasma irregularities in the ionosphere based on CHAMP observations, Front. Phys., 2, 15, https://doi.org/10.3389/fphy.2014.00015, 2014.

Ma, G. and Maruyama, T.: A super bubble detected by dense GPS network at east Asian longitudes, Geophys. Res. Lett., 33, L21103, https://doi.org/10.1029/2006GL027512, 2006.

Morse, F. A., Edgar, B. C., Koons, H. C., Rice, C. J., Heikkila, W. J., Hoffman, J. H., Tinsley, B. A., Winningham, J. D., Christensen, A. B., Woodman, R. F., Pomalaza, J., and Teixeira, N. R.: Equion, an equatorial ionospheric irregularity experiment, J. Geophys. Res., 82, 578-592, https://doi.org/10.1029/JA082i004p00578, 1977.

Ngwira, C. M., Seemala, G. K., and Bosco Habarulema, J.: Simultaneous observations of ionospheric irregularities in the African low-latitude region, J. Atmos. Sol.-Terr. Phy., 97, 50-57, https://doi.org/10.1016/j.jastp.2013.02.014, 2013.

Nishioka, M., Saito, A., and Tsugawa, T.: Occurrence characteristics of plasma bubble derived from global groundbased GPS receiver networks, J. Geophys. Res., 113, A05301, https://doi.org/10.1029/2007ja012605, 2008.

Nishioka, M., Basu, S., Basu, S., Valladares, C. E., Sheehan, R. E., Roddy, P. A., and Groves, K. M.: C/NOFS satellite observations of equatorial ionospheric plasma structures supported by multiple ground-based diagnostics in October 2008, J. Geophys. Res., 116, A10323, https://doi.org/10.1029/2011ja016446, 2011.

Ossakow, S. L.: Ionospheric irregularities, Rev. Geophys., 17, 521533, https://doi.org/10.1029/RG017i004p00521, 1979.

Otsuka, Y., Shiokawa, K., Ogawa, T., Yokoyama, T., Yamamoto, M., and Fukao, S.: Spatial relationship of equatorial plasma bubbles and field-aligned irregularities observed with an all-sky airglow imager and the Equatorial Atmosphere Radar, Geophys. Res. Lett., 31, L20802, https://doi.org/10.1029/2004GL020869, 2004.

Park, J., Noja, M., Stolle, C., and Lühr, H.: The Ionospheric Bubble Index deduced from magnetic field and plasma observations onboard Swarm, Earth, Planet Space, 65, 1333-1344, https://doi.org/10.5047/eps.2013.08.005, 2013.

Rastogi, R. G., Koparkar, P. V., Chandra, H., and Vyas, G. D.: Spread-F and radio wave scintillations near the F-region anomaly crest, Ann. Geophys., 7, 281-284, 1989.

Reinisch, B., Huang, X., Galkin, I., Paznukhov, V., and Kozlov, A.: Recent advances in real-time analysis of ionograms and ionospheric drift measurements with digisondes, J. Atmos. Sol.-Terr. Phy., 67, 1054-1062, https://doi.org/10.1016/j.jastp.2005.01.009, 2005.

Reinisch, B. W., Scali, J. L., and Haines, D. L.: Ionospheric drift measurements with ionosondes, Annales of Geophysics, 41, 695-702, https://doi.org/10.4401/ag-3812, 1998.

Rino, C. L., Carrano, C. S., Groves, K. M., and Roddy, P. A.: A characterization of intermediate-scale spread $\mathrm{F}$ structure from four years of high-resolution C/NOFS satellite data, Radio Sci., 51, 779-788, https://doi.org/10.1002/2015rs005841, 2016.

Roddy, P. A., Hunton, D. E., Ballenthin, J. O., and Groves, K. M.: Correlation of in situ measurements of plasma irregularities with ground-based scintillation observations, J. Geophys. Res., 115, A06303, https://doi.org/10.1029/2010JA015288, 2010.

Schunk, R. W. and Nagy, A. F.: Ionospheres: physics, plasma physics, and chemistry, Cambridge Atmospheric and Space Science Series, Cambridge, Cambridge, 2 Edn., 642 pp., 2009. 
Shi, J. K., Wang, G. J., Reinisch, B. W., Shang, S. P., Wang, X., Zherebotsov, G., and Potekhin, A.: Relationship between strong range spreadFand ionospheric scintillations observed in Hainan from 2003 to 2007, J. Geophys. Res., 116, A08306, https://doi.org/10.1029/2011ja016806, 2011.

Siefring, C. L., Bernhardt, P. A., Roddy, P. A., and Hunton, D. E.: Comparisons of equatorial irregularities measurements from C/NOFS: TEC using CERTO and CITRIS with in-situ plasma density, Geophys. Res. Lett., 36, L00C08, https://doi.org/10.1029/2009GL038985, 2009.

Smith, J. M., Rodrigues, F. S., and de Paula, E. R.: Radar and satellite investigations of equatorial evening vertical drifts and spread F, Ann. Geophys., 33, 1403-1412, https://doi.org/10.5194/angeo-33-1403-2015, 2015.

Smith, J. M., Rodrigues, F. S., Fejer, B. G., and Milla, M. A.: Coherent and incoherent scatter radar study of the climatology and day-to-day variability of mean $\mathrm{F}$ region vertical drifts and equatorial spread F, J. Geophys. Res., 121, 1466-1482, https://doi.org/10.1002/2015JA021934, 2016.

Space Physics Data Facility: available at: https://cdaweb.gsfc.nasa. gov/, last access: 30 September 2020.

Sripathi, S., Bose, S., Patra, A. K., Pant, T. K., Kakad, B., and Bhattacharyya, A.: Simultaneous observations of ESF irregularities over Indian region using radar and GPS, Ann. Geophys., 26, 3197-3213, https://doi.org/10.5194/angeo-26-3197-2008, 2008.

Stolle, C., Lühr, H., Rother, M., and Balasis, G.: Magnetic signatures of equatorial spread $\mathrm{F}$ as observed by the CHAMP satellite, J. Geophys. Res., 111, A02304, https://doi.org/10.1029/2005JA011184, 2006.

Sultan, P. J.: Linear theory and modeling of the RayleighTaylor instability leading to the occurrence of equatorial spread F, J. Geophys. Res., 101, 26875-26892, https://doi.org/10.1029/96JA00682, 1996.

Tsunoda, R. T.: On the spatial relationship of 1-m equatorial spread F-irregularities and plasma bubbles, J. Geophys. Res., 85, 185190, https://doi.org/10.1029/JA085iA01p00185, 1980.

Tsunoda, R. T., Livingston, R. C., McClure, J. P., and Hanson, W. B.: Equatorial plasma bubbles - Vertically elongated wedges from the bottomside F layer, J. Geophys. Res., 87, 9171-9180, https://doi.org/10.1029/JA087iA11p09171, 1982.

University of Massachusetts Lowell Center for Atmospheric Research (UMLCAR): available at: http://ulcar.uml.edu/SAO-X/ SAO-X.html, last access: 30 September 2020.
Wan, X., Xiong, C., Rodriguez-Zuluaga, J., Kervalishvili, G. N., Stolle, C., and Wang, H.: Climatology of the Occurrence Rate and Amplitudes of Local Time Distinguished Equatorial Plasma Depletions Observed by Swarm Satellite, J. Geophys. Res., 123, 3014-3026, https://doi.org/10.1002/2017JA025072, 2018.

Wang, G., Shi, J., Wang, X., and Shang, S.: Seasonal variation of spread-F observed in Hainan, Adv. Space Res., 41, 639-644, https://doi.org/10.1016/j.asr.2007.04.077, 2008.

Wang, G. J., Shi, J. K., Reinisch, B. W., Wang, X., and Wang, Z.: Ionospheric plasma bubbles observed concurrently by multiinstruments over low-latitude station Hainan, J. Geophys. Res., 120, 2288-2298, https://doi.org/10.1002/2014JA020245, 2015.

Woodman, R. F. and La Hoz, C.: Radar observations of F region equatorial irregularities, J. Geophys. Res., 81, 5447-5466, https://doi.org/10.1029/JA081i031p05447, 1976.

Xiong, C., Stolle, C., Juan, R. Z., and Siemes, C.: Losses of GPS signals onboard the Swarm satellites and its relation to strong plasma depletions, AGU Fall Meeting Abstracts, SA12A-01, 2016.

Xiong, C., Stolle, C., LÜhr, H., Park, J., Fejer, B. G., and Kervalishvili, G. N.: Scale analysis of equatorial plasma irregularities derived from Swarm constellation, Earth Planet Space, 68, 121, https://doi.org/10.1186/s40623-016-0502-5, 2016.

Yeh, K. C. and Liu, C.-H.: Radio wave scintillations in the ionosphere, IEEE Proceedings, 70, 324-360, https://doi.org/10.1109/proc.1982.12313, 1982.

Zakharenkova, I., Astafyeva, E., and Cherniak, I.: GPS and in situ Swarm observations of the equatorial plasma density irregularities in the topside ionosphere, Earth Planet Space, 68, 120, https://doi.org/10.1186/s40623-016-0490-5, 2016.

Zhan, W., Rodrigues, F. S., and Milla, M. A.: On the Genesis of Postmidnight Equatorial Spread F : Results for the American/Peruvian Sector, Geophys. Res. Lett., 45, 7354-7361, https://doi.org/10.1029/2018gl078822, 2018.

Zhang, Y., Wan, W., Li, G., Liu, L., Hu, L., and Ning, B.: A comparative study of GPS ionospheric scintillations and ionogram spread F over Sanya, Ann. Geophys., 33, 1421-1430, https://doi.org/10.5194/angeo-33-1421-2015, 2015.

Zuo, X., Yu, T., and Xia, C.: A study of simultaneous scintillation observations by Chinese FY-2 geostationary meteorological satellite and VHF coherent radar measurements over South China, AGU Fall Meeting Abstracts, SA13A-2111, 2016. 